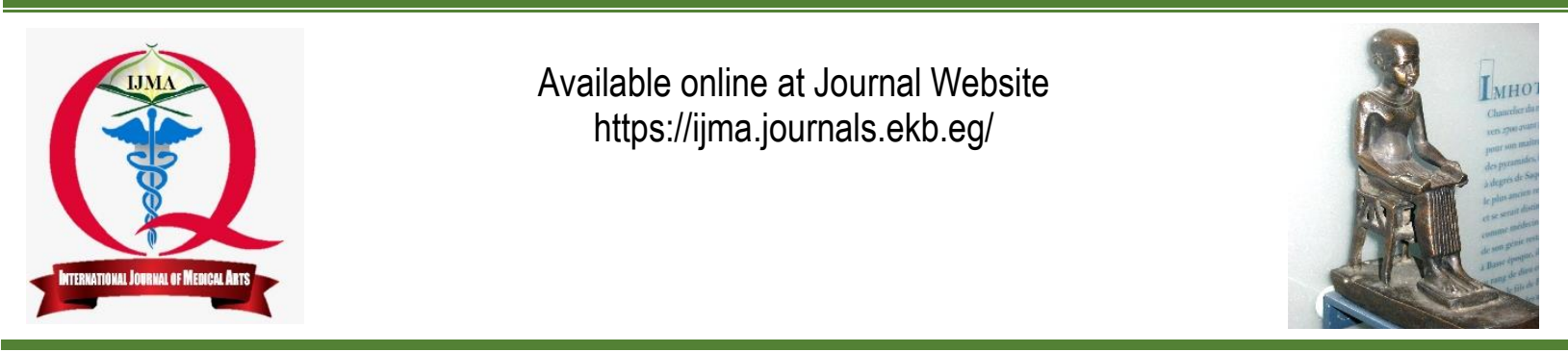

Original article

\title{
Histological and Immunohistochemical Studies on the Role of Stem Cells on the Burned Skin of Adult Male Albino Rats
}

\author{
Fatma M. Abd Allah' ${ }^{a}$, Ashraf M. Moustafab ${ }^{b}$, Lotfy S. Moahmmed ${ }^{b}$, Ezz El-Dein E. Abd Allahª \\ Department of Histology, Damietta Faculty of Medicine, Al-Azhar University, Egypt ${ }^{[a]}$ \\ Department of Histology, Faculty of Medicine, Al-Azhar University, Egypt ${ }^{[b]}$ \\ Corresponding author: Fatma M. Abd Allah \\ Email: fatma.mamhisto@domazhermedicine.edu.eg \\ Received at: December 1, 2019; Revised at: January 31, 2020; Accepted at: January 31, 2020; Available online at: February 1, 2020 \\ DOI: 10.21608/ijma.2020.20386.1050
}

\section{ABSTRACT}

Background: Mesenchymal stem cells have delivered new approaches to the management of burn healing in severe skin injuries.

Aim of the work: To evaluate the effect of bone marrow-derived mesenchymal stem cells [BMSCs] on healing of induced deep 2 nd degree skin burns in albino rats.

Methodology: 55 male albino rats weighed $200 \mathrm{gm}$ were divided into 5 groups, 5 animals in group I [control] and group II [burn model], 15 animals in group III [untreated], group IV and group V [MSCs treated]. Groups III, IV and V were subdivided into 3 subgroups that were sacrificed after 7, 14 and 21 days respectively. Deep 2nd degree burn wounds were induced on a $4 \mathrm{~cm} 2$ area on the back of rats in groups II, III, IV and V by brass probes stabilized at $88-90^{\circ} \mathrm{C}$ and contacted to the shaved dorsal skin of rats for 20 seconds without exerting any external pressure. Mesenchymal stem cells were isolated from the bone marrow of 5 young rats, weighed $100 \mathrm{gm}$ then intra-dermally and intraperitoneally injected.

Results: By the end of the third week, the wounds of BMSCs-treated groups showed full regeneration of epidermis, re-organization of collagen and decrease in VEGF immunopositive cells. Delayed wound healing was seen in $20 \%$ of systemically treated rats. Significant increase in the mean area percent of collagen fibers was detected in topically treated group.

Conclusion: Both methods of BMSCs injection were effective in healing of full thickness skin wound but topical method was more effective.

Keywords: Stem cells; Skin; Vascular endothelial growth factor; Wound healing; Scar.

This is an open access article under the Creative Commons license [CC BY] [https://creativecommons.org/licenses/by/2.0/]

Please cite this article as Abd Allah FM, Moustafa AM, Moahmmed LS, Abd Allah EE. Histological and Immunohistochemical Studies on the Role of Stem Cells on the Burned Skin of Adult Male Albino Rats. IJMA 2020; 2[1]: 265-291. 


\section{INTRODUCTION}

Skin is the body's largest organ, generally comprising 15 to $20 \%$ of total body weight. In adults, it has a surface area of about 1.5 to 2 meters to the outside world. It is also known as the cutaneous or integument layer. ${ }^{[1]}$

Burns are traumatic injuries to the skin that can occur in the home or workplace. Burns are divided into different degrees: the first degree affecting only the epidermis, the superficial second degree affecting the epidermis and papillary dermis, while the deep second degree affecting the epidermis, papillary dermis and reticular dermis, the third degree of burn involving the full skin thickness and underlying muscles. ${ }^{[2]}$ In general, thermal skin injury is characterized by variable necrosis and cell injury. Burn wounds evolve in depth and size in the first few days after injury, leading to loss of the integrity of the skin. [3]

Burn patient may experience a number of complications such as shock, infection, electrolyte imbalance and respiratory failure [4]. The first step for burn therapy is to promote healing as early as possible.[5]

The topical agent of choice in severe burns is Silver sulfadiazine [SSD] [composed of silver nitrate and mafenide acetate] and is used universally today. Although SSD cream is safe [6], during the healing process of deep partial thickness burns treated by the skin substitutes like autologous skin grafts or tissue engineered skin, wound contraction and scar formation are unavoidable. ${ }^{[7]}$ MSCs improved the process of burn healing, reduced the formation of scars and re-established the normal function of the skin and its appendages [8]. In skin wound healing, angiogenesis is necessary for formation of new granulation tissue in the proliferative phase ${ }^{[9]}$.

Vascular endothelial growth factor [VEGF], a highly potent angiogenic factor that can regulate and increase microvasculature that enhances vascular permeability, induces chemotaxis and activation of monocytes, macrophages and promotes growth of vascular endothelial cells. So, this factor had implicated in the wound healing process ${ }^{[10] .}$

\section{AIM OF THE WORK}

The aim of this work is to evaluate the effect of bone marrow-derived mesenchymal stem cells [BMSCs] on healing of induced deep $2^{\text {nd }}$ degree skin burns in albino rats.

\section{MATERIALS AND METHODS}

\section{A-Materials}

1-Isolation, culture and labeling of MSCs from rat Bone marrow: Bone marrow cells were collected by aspiration from the long bones of the 8-week-old male albino rat. Bones have been flushed with Dulbecco's Modified Eagle Medium [DMEM] [Sigma, USA, D5796] combined with 10 percent bovine fetal serum [FBS] [Sigma, USA, F6178]. In sterile conical tubes, the bone marrow was gradually poured over Ficoll-Hypaque [Sigma, USA, F8016] and centrifuged [at 1,200 rpm] for 30 minutes at room temperature]. The opaque surface containing mononuclear cells was aspirated and resuspended in a full culture medium complemented by $1 \%$ penicillinstreptomycin [Sigma, USA, P4333]. Cells have been incubated for 14 days at $37^{\circ} \mathrm{C}$ in $5 \%$ humidified $\mathrm{CO}_{2}$. Media has been changed every three to four days. Cultures were washed twice with phosphate buffer saline[PBS] [P5493, Sigma, USA] when large colonies formed [ 80 to $90 \%$ confluence] and cells were trypsinized with $0.25 \%$ trypsin [Sigma, USA, T1426] in $1 \mathrm{ml}$ ethylene diamine tetra acetate [EDTA] [Sigma, USA, E6758] for 5 minutes at $37^{\circ} \mathrm{C}$. Cell pellets were resuspended with serum-supplemented medium after centrifugation [at $2.400 \mathrm{rpm}$ for 20 minutes at room temperature] and incubated in $25 \mathrm{~cm}^{2}$. Flasks of art [Sigma, USA, C6356]. The resulting cultures have been referred to as cultures of the first passage. Cultural MSCs have been characterized by plastic adhesivity and fusiform shape ${ }^{[11]}$.

\section{2-Burn creation:}

Animals were subjected to deep seconddegree skin burns by brass probes. The brass disc was a $2 \mathrm{~cm}$ diameter, stabilized at $88-90^{\circ} \mathrm{C}$ and contacted to the shaved dorsal skin of rats for 20 seconds without exerting any external pressure [Figure 1b]. All animals were immediately 
resuscitated with lactated Ringer's solution [2 $\mathrm{ml} / 100 \mathrm{~g}$ body weight] applied intraperitoneally [12].
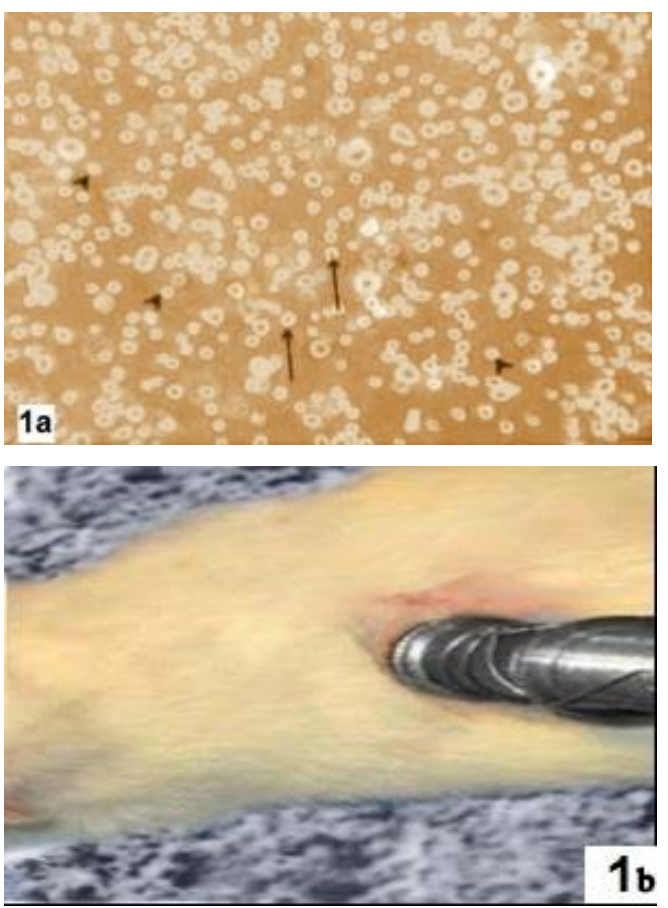

Figure [1a]: A photomicrograph of of bone marrow-derived mesenchymal stem cells of rat primary culture at 1 day of isolation and culture showing bone marrow cells that are variable in size, shape, and arrangement. Most of the cells are rounded [arrows] and arranged to form chains, whereas some cells appear dispersed and separated [arrow heads] [Inverted microscope, X 100]. Figure [1b] A Photograph showing the brass used in inducing the burn injury.

\section{3-Experimental animals:}

The present study was carried out on 55 adult local strain male albino rats with average weight of $200 \mathrm{Gm}$ and the experimental protocol of the study was approved by the ethical committee of Faculty of Medicine [boys], Al-Azhar University [Cairo]. All Rats were fed on ordinary rat diet and dived into 5 groups.

\section{4-Animal grouping:}

Group I: 5 Rats received no treatment and served as control group.

Group II [burn model group]: consisted of 5 rats that served as a deep second-degree skin burn.

Group III: consisted of 15 rats that were subjected to burn as in group II. The burned area was covered with Vaseline gauze and silver sulfadiazine ointment. The Vaseline gauze and ointment were changed every day in complete aseptic conditions until the day of the scarification. Animals of this group were further subdivided into 3 subgroups, 5 animals each: Subgroup III.A: sacrificed at day 7 post burn. Subgroup III.B: sacrificed at day 14 post burn. Subgroup III.C: sacrificed at day 21 post burn.

Group IV: consisted of 15 rats that were subjected to burn as in group-II. One hour after burn, a suspension of $1 \times 10^{6}$ BM-MSCs in $0.5 \mathrm{ml}$ PBS was injected intradermal into the dermis of the burned area at 4 sites around the burn [11, 16]. Animals of this group were further subdivided equally into 3 subgroups, five animals each: Subgroup IV.A: sacrificed at day 7 post burn. Subgroup IV.B: sacrificed at day 14 post burn. Subgroup IV.B: sacrificed at day 21 post burn.

Group V: consisted of 15 rats that were subjected to burn as in group II. One hour after burn, a suspension of $1 \times 106$ BM-MSCs in $0.5 \mathrm{ml}$ PBS was injected intraperitoneally [18]. Animals of this group were further subdivided equally into 3 subgroups, five animals each: Subgroup V.A: sacrificed at day 7 post burn. Subgroup V.B: sacrificed at day 14 post burn. Subgroup V.C: sacrificed at day 21 post burn. The burns were photographed at days $0,7,14$ and 21 with the rats in a standard prone position by using digital camera [Samsung].

\section{B- Methods}

\section{1- Histological study:}

1-Light microscopic examination: Slides were stained with Hematoxylin \& Eosin, Masson's trichrome and Immunohistochemical stains and examined using a light microscope [13,14,15].

\section{2 -Statistical analysis:}

Skin areas of burn were subjected to the following measurements: Blood vessels count, Macrophage count, Fibroblast count, Mean area percent of collagen fibers and Mean area percent of VEGF immune positive cells. The Statistical data included were expressed as mean, standard error [SE] standard deviation [SD \pm ] \& the student $T$ test was used to elucidate the differences 
Abd Allah FM, et al.

between the treated groups and control group. The obtained data were analyzed by using SPSS software [Version 15].

\section{RESULTS \\ 1-Naked eye examination of the burned skin:}

The skin area of the control [group. I] showed no apparent change. The burned model area [Group II] [Figure 2]. In group-III, [Figure 3]. BMMSCs treated groups, group. IV [Figure a.b.c] and group V [Figure 4 d.e.f].

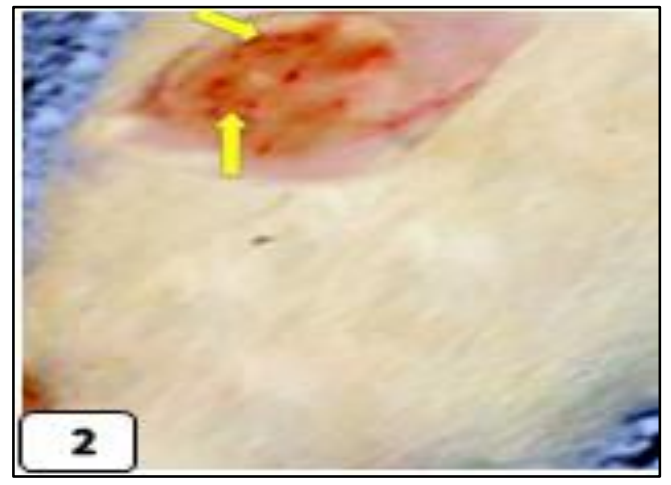

Figure [2]: A photograph of the burned model [group. II] Showing greyish white area with smooth raised edges. The skin surrounding the edges appear reddish in color. Notice: exfoliation and necrosis in the central part of the burned area.

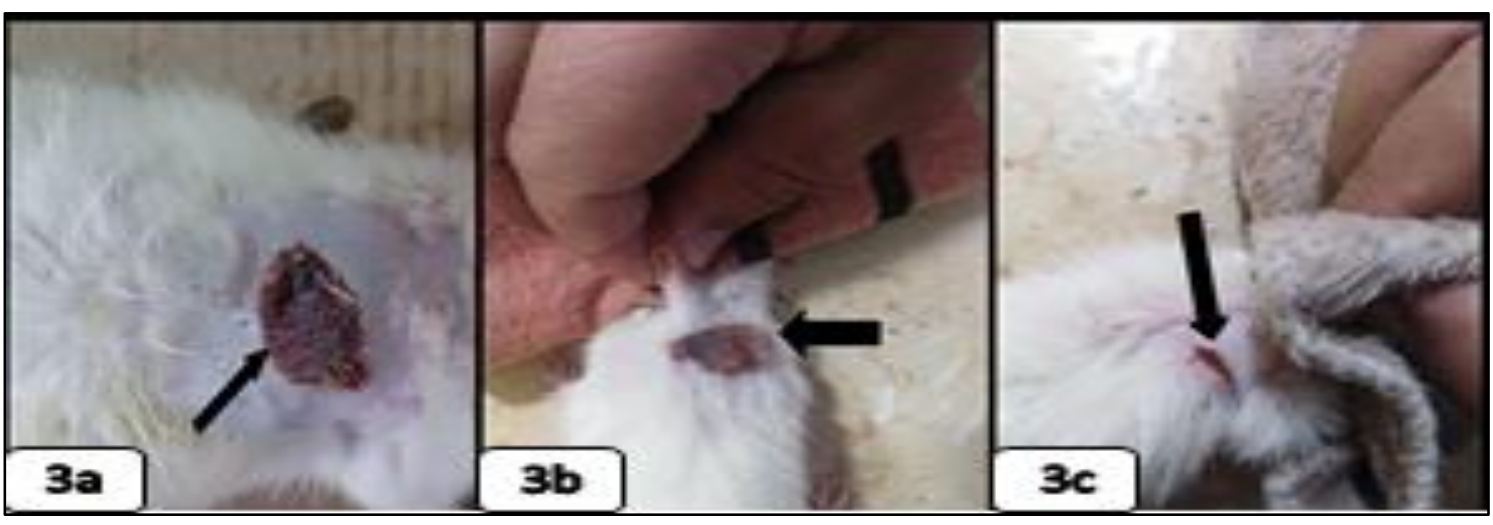

Figure [3] A: photograph of the burned skin of group. III showing that in subgroup IIIA and IIIB, the burned area is covered with a scab [arrow]. In subgroup III.C, the scab is separated [arrow] and the burned area is covered by a red granular tissue while the adjacent area shows complete healing.

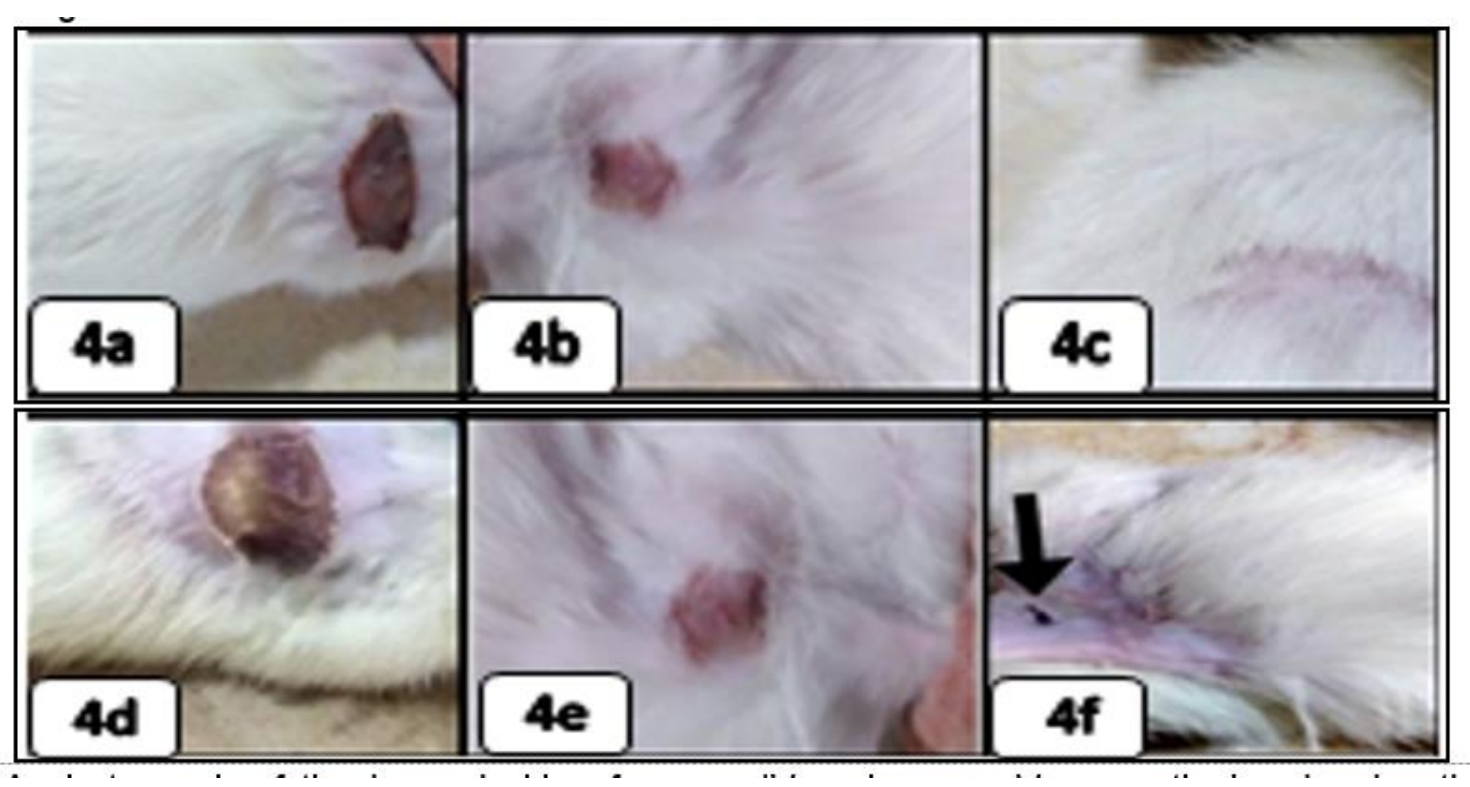

Figure $[4 a, b, c, d, e, f] A$ photograph of the burned skin of group .IV and group .V respectively, showing the burned area in subgroup IV.A and subgroup V.A appear covered by thick scab. In subgroup IV.B and subgroup V.B, the area is apparently smaller in size with no scab. The burned area in subgroup IV.C and subgroup V.C is markedly smaller in size, the edges are showing epidermal coverage and hair regrowth. Delayed healing is seen in small part of the burn [arrow] in subgroup V.C. 


\section{2-Microscopic examination:}

\section{Group I [Control]:}

Light microscopic examination of skin sections of control adult male albino rats [G.I] showed the normal structure of the thin skin, it appeared formed of thin epidermis and thick dermis [Figures. 5\&6].

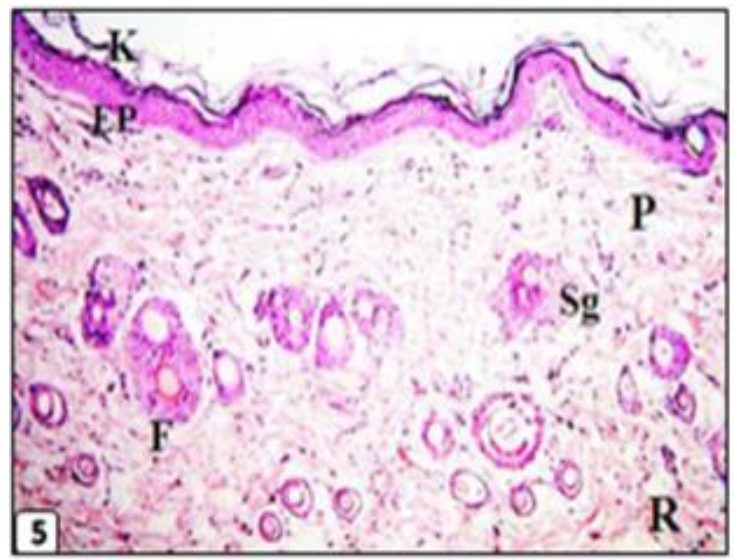

Figure [5]. A photomicrograph of a skin section of control group of adult male albino rat [G.I] showing normal epidermis formed of keratinized stratified squamous epithelium [Ep] and dermis. The dermis consists of superficial papillary layer $[\mathrm{P}]$ and deeper reticular one $[R]$. The lower part is occupied by hypodermis full of fat cells. Notice: Sebaceous glands [Sg] and hair follicles [F] are seen in the mid to upper dermis and some were seen near to the hypodermis. [Group. I: $\mathrm{H}$ and $\mathrm{E} ; \mathrm{x} 100]$.

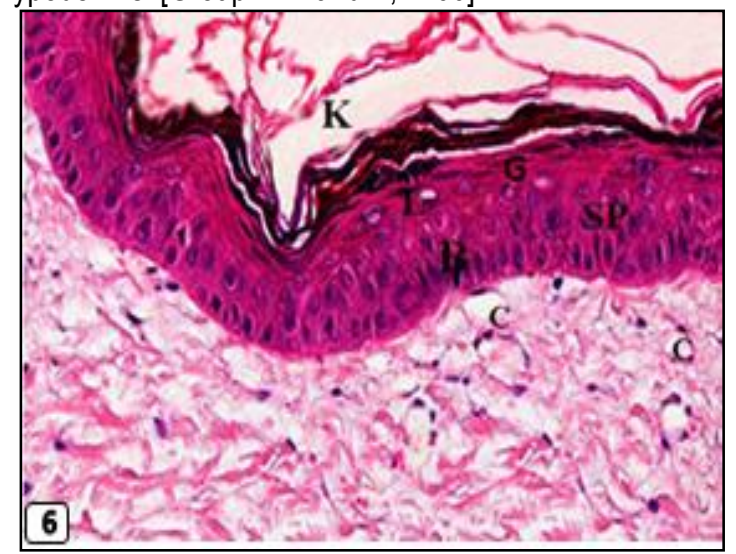

Figure [6]. A photomicrograph of a skin section of control group of adult male albino rat [G.I] showing normal epidermis formed of stratum basale [B], 2-3 layers of stratum spinosum [SP], 2-3 layers of stratum granulosum [G] and keratin $[K]$. Langerhans' cells $[\mathrm{L}]$ are found among the keratinocytes. Numerous blood capillaries [c] in the papillary layer are seen. [Group I: $\mathrm{H}$ and E; $\mathrm{x} 400$ ].

The epidermis was composed of stratified squamous epithelium formed mainly of keratinocytes which rested on wavy basement membrane. The border between the epidermis and dermis was clearly demarcated [Figures. 5 and 6]. Many rounded cells with deeply stained nucleus that were surrounded by clear halo were present in the stratum spinosum probably nonkeratinocytes [Langerhans cells] [Figure 6]. The underlying papillary layer of dermis showed fine collagen fibers, patent capillaries and many connective tissue cells [Figure 6]. The lower part occupied by hypodermis was full of fat cells [Figure 5]. The dermis contained hair follicles with its associated sebaceous [Figure 5]. Masson's trichrome stained sections showed the normal density and distribution of the collagen fibers in the dermis [Figure 7]. In Immunohistochemical stained sections, revealed positive V.EGF reaction in the wall of blood vessel of the dermis. [Figure 8].

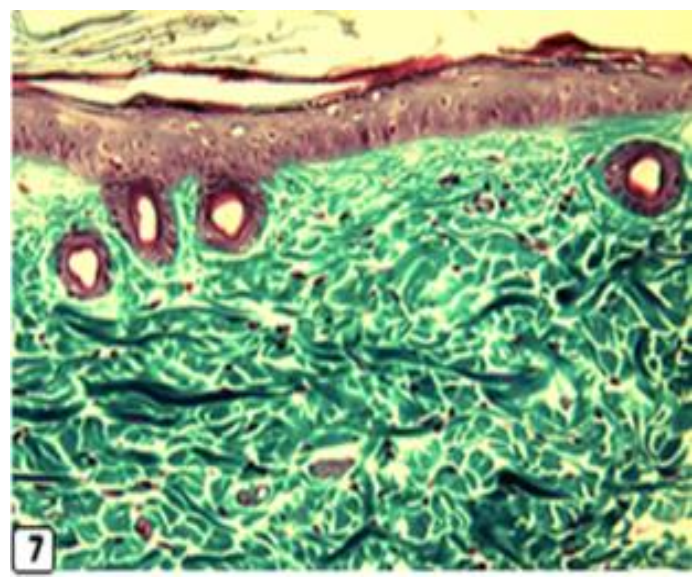

Figure [7] A photomicrograph of a skin section of control group of adult male albino rat [G.I] showing the normal density and distribution of the collagen fibers in the dermis. [Group. I: Masson's trichrome; x 400]

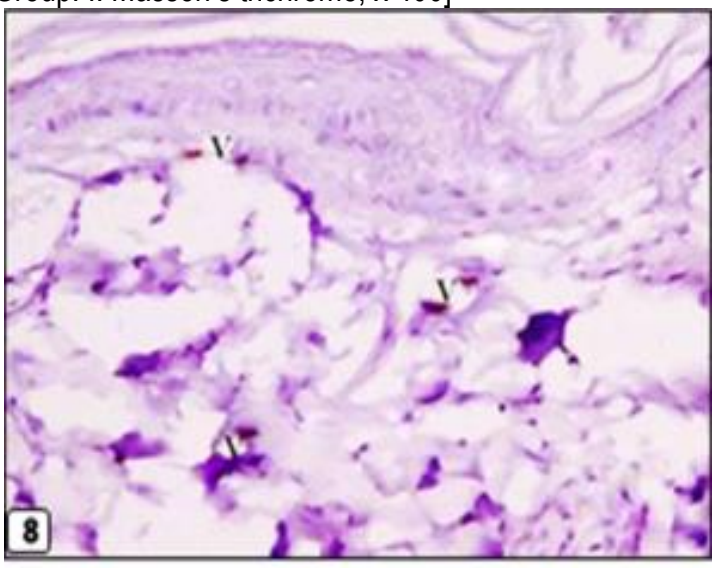

Figure [8]: A photomicrograph of a skin section of control group of adult male albino rat [G.I] showing positive reaction in the wall of blood vessel of the dermis. [Group. I: Avidinbiotin peroxidase stain with $\mathrm{Hx}$ counter stain; $\mathrm{x} 400]$. 


\section{ii-Group. II [burn model]:}

Light microscopic examination of burned skin sections of adult male albino rats [G.II] showed no epidermis and the two edges of the burn were widely separated [Figure 9] and tissue debris in between. The damaged hair follicles appeared with lost architecture leaving empty spaces [Figures $9 \& 10]$. The dermis showed empty spaces [edema] and acidophilic fused collagen fibers with loss of collagen fibers distinction [Figure 10]. Masson trichrome stained sections showed that collagen fibers lost their distinction in the dermis. The upper dermis was stained red unlike the usual green stain [Figure11]. Immunohistochemical stained sections showed negative immune-reaction for VEGF as blood vessels were not encountered through the examination of the upper part of the dermis [Figure12]

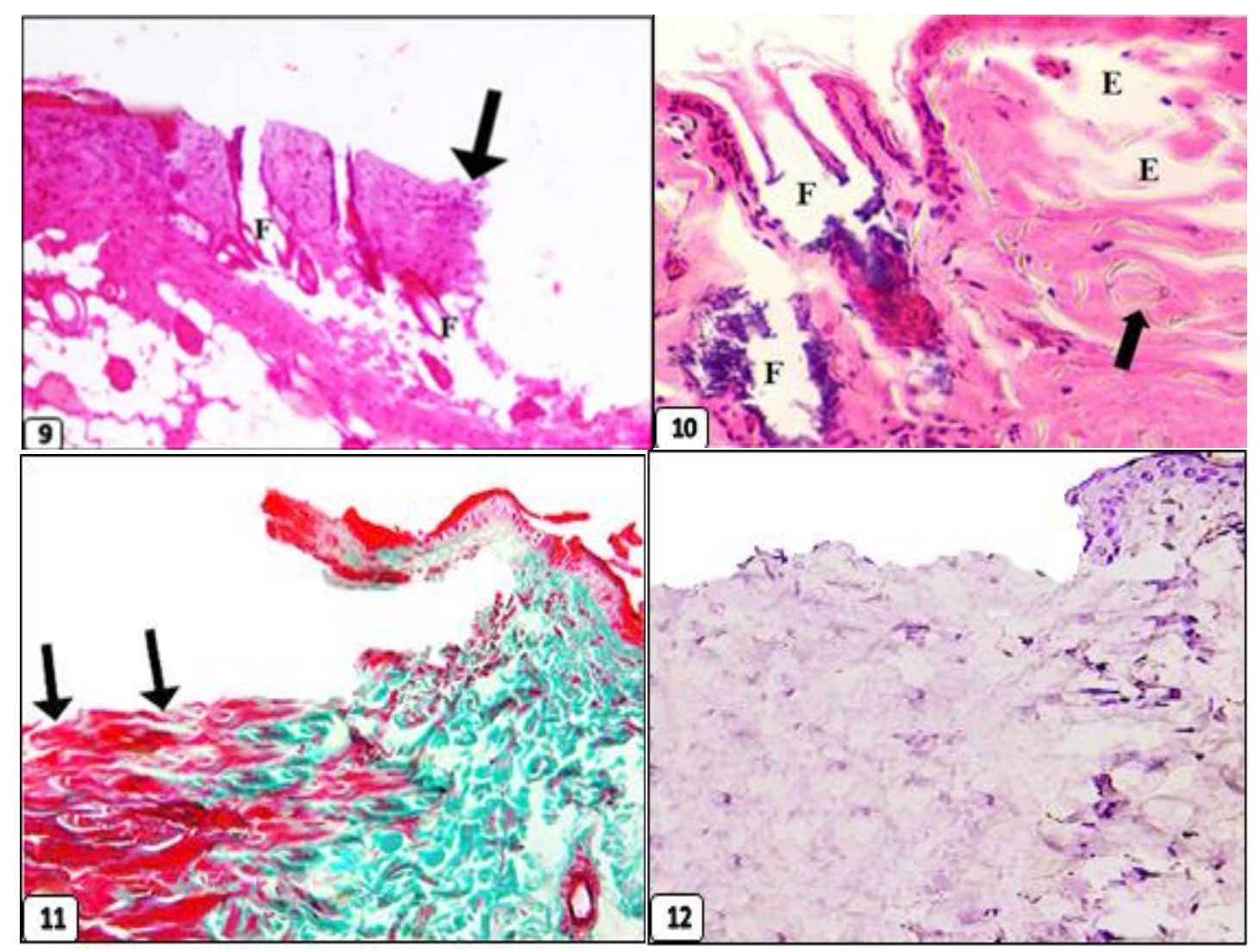

Figure [9] A photomicrograph of a section of burned skin of adult male albino rat [G.II] showing no epidermis, wide spacing of burn edges[arrow] and tissue debris in between[astrix]. Notice: The damaged hair follicles [F] with lost architecture. [Group. II: $\mathrm{H}$ and $\mathrm{E} ; \mathrm{x} 100$ ]. Figure [10] A photomicrograph of a section of burned skin of adult male albino rat [G.II] showing the damaged hair follicles[F] appear with lost architecture and empty spaces[E]. Notice: Acidophilic fused collagen fibers with loss of collagen fibers distinction [arrow]. [Group. II: $\mathrm{H}$ and E; x400]. Figure [11] A photomicrograph of a section of burned skin of adult male albino rat [G.II] showing the collagen fibers in the burned area stained red and lost their distinction [arrows]. Notice: The collagen fibers in the non-burned part stained green. [Group. II: Masson's trichrome; $x$ 400]. Figure [12] A photomicrograph of a section of burned skin of adult male albino rat [G.II] showing negative immunoreaction for VEGF [Group. II: Avidin-biotin peroxidase stain with $\mathrm{Hx}$ counter stain; $\mathrm{x} 400]$.

\section{iii-Group. III:}

\section{Subgroup III.A:}

Light microscopic examination of hematoxylin and eosin stained sections of the burned skin 7 days after burn induction showed an epidermal loss and a scab was formed that covered the wounded area. The scab was acidophilic structure [Figure13]. Beneath the scab, granulation tissue was observed filling the burn gap with many spaces [Figure13]. The granulation tissue was formed of a combination of cellular elements, newly formed small blood vessels [angiogenesis] 
embedded in loose extracellular matrix of collagen

[Figure 14]. Adipocytes were encountered in the granulation tissue. The cellular elements of the granulation tissue included polymorph nuclear leucocytes, lymphocytes, macrophages and fibroblasts. The macrophages exhibited a large indented nucleus. Extravasation of red blood cells was evident in the granulation tissue. [Figure14].
Masson trichrome stained sections showed few dispersed interrupted thin collagen fibers were demonstrated in the granulation tissue [Figure15]. Immunohistochemical stained sections showed localized immunoreactivity in the mononuclear cells and endothelial cells of blood vessels [Figure 16].

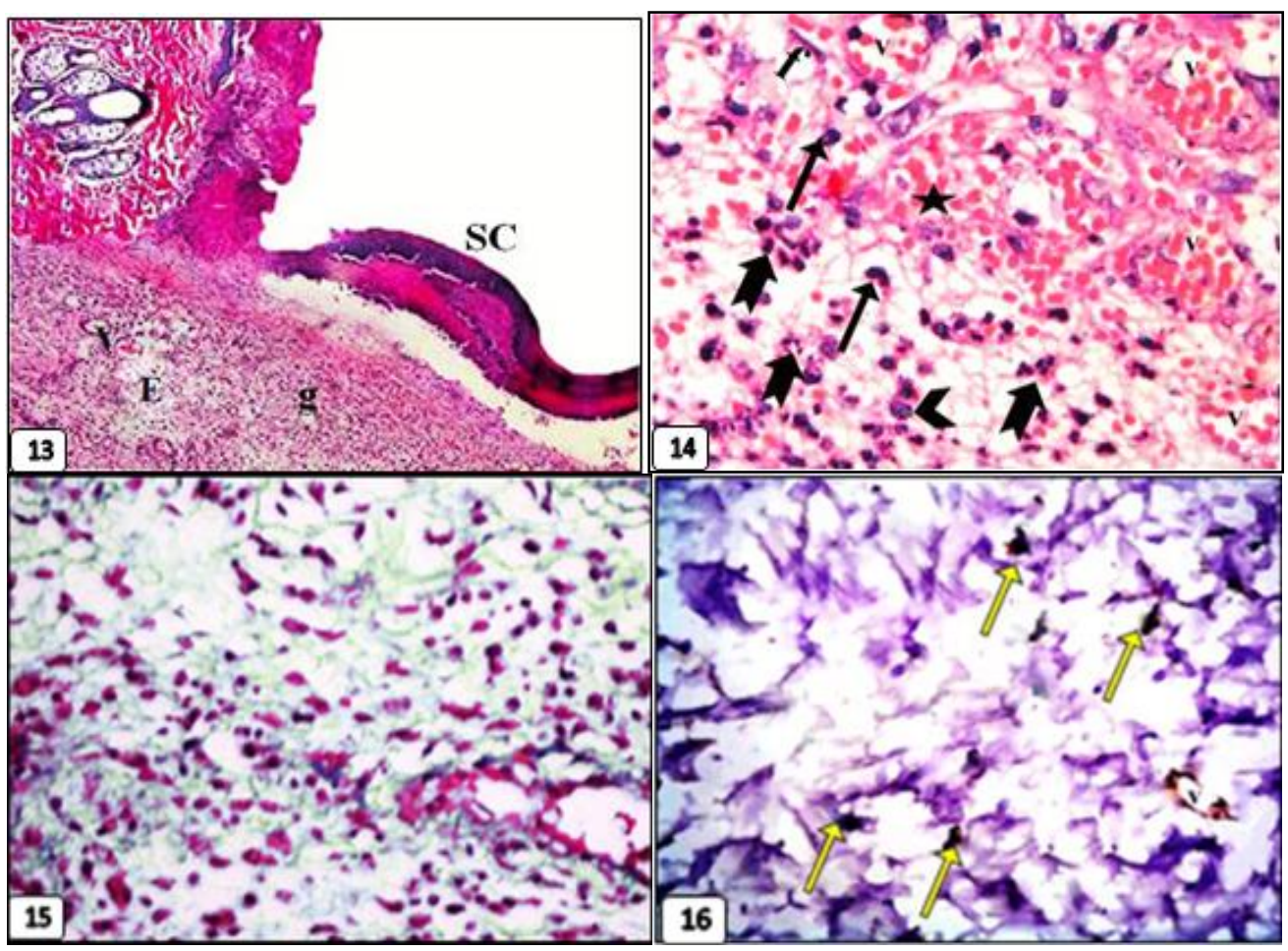

Figure [13]A photomicrograph of a section of the burned skin 7 days after burn induction showing the site of the burn and adjacent nearby normal skin. The burn area is covered by scab [Sc] beneath which the granulation tissue [g] is observed with empty spaces [E]. The granulation tissue [g] exhibits newly formed small blood vessels [v]. [Subgroup III.A: $\mathrm{H}$ and E; $\mathrm{x}$ 100]. Figure [14] A photomicrograph of a section of the burned skin 7 days after burn induction showing that the granulation tissue contains many polymorphonuclear cells [notched arrows], macrophages [arrows] lymphocyte [arrow head] and blood vessels [V] with extravasated red blood cells [astrix]. Note: fat cells within the granulation tissue. [Subgroup III.A: H and E; x 600]. Figure [15] A photomicrograph of a section of the burned skin 7 days after burn induction showing few scattered collagen fibers [green coloration] in the granulation tissue at the site of the burn. [Subgroup III.A: Masson's trichrome; x400]. Figure [16] A photomicrograph of a section of the burned skin 7 days mild localized immunoreactivity in the mononuclear cells [arrows] and endothelial cells of blood vessels "V". [Subgroup III.A: Avidin-biotin peroxidase stain with Hx counter stain; x 400].

\section{Subgroup III.B:}

Light microscopic examination of hematoxylin and eosin stained sections of the burned skin14 days after burn induction showed that the scab was still present [Figure17]. Beneath the scab there was evident growth of epidermis over the edges of the wound [re epithelialization]. The newly formed epidermis showed immature differentiation [Figure17]. The underlying granulation tissue showed persistence of inflammation with occurrence of many polymorph nuclear cells [Figure 18]. Also, numerous blood vessels, fibroblasts and macrophages were observed [Figure 18]. Masson trichrome stained sections showed few collagen fibers were observed in the granulation tissue. They were haphazardly arranged [Figure19]. Immunohistochemical staining for VEGF showing moderate localized immune reactivity in the mononuclear cells, fibroblast and the endothelial cells of blood vessels [Figure 20]. 

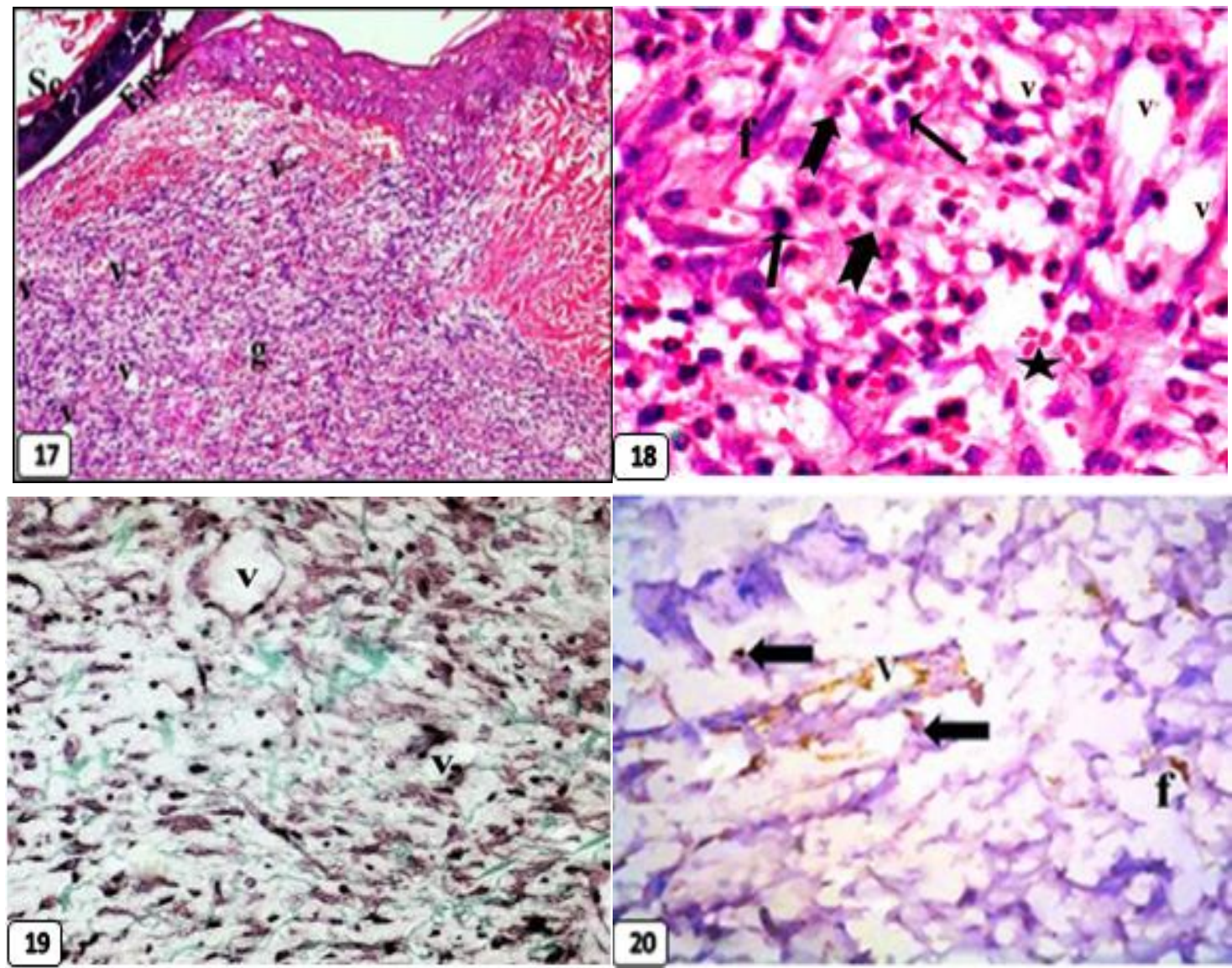

Figure [17]. A photomicrograph of a section of the burned skin 14 days after burn induction showing re-epithelialization [Ep] beneath the scab [Sc]. The granulation tissue [g] exhibits numerous blood vessels [v]. Notice: The newly formed epidermis shows poorly differentiated layers. [Subgroup IIIB: $\mathrm{H}$ and E; $x$ 100]. Figure [18].A photomicrograph of a section of the burned skin 14 days after burn induction showing that the granulation tissue contains many polymorphnuclear cells [notched arrows], macrophages [arrows], few fibroblasts [f], numerous blood vessels[v] and extravasated red blood cells[astrix].[Subgroup III.B: $\mathrm{H}$ and $\mathrm{E} ; \mathrm{x600}$ ]. Figure [19].A photomicrograph of a section of the burned skin 14 days after burn induction showing few collagen fibers are observed in the granulation tissue. They are haphazardly arranged. Notice: The numerous blood vessels [v]. [Subgroup III.B: Masson's trichrome .X400]. Figure [20].A photomicrograph of a section of the burned skin 14 days after burn induction showing moderate localized immune reactivity in the mononuclear cells [arrows], fibroblast [f] and endothelial cells of blood vessels[V] .[Subgroup III.B: Avidin-biotin peroxidase stain with Hx counter stain; x 400].

\section{Subgroup III.C:}

Light microscopic examination of hematoxylin and eosin stained sections of the burned skin21 days after burn induction revealed complete absence of the scab. The newly formed thick epidermis extended from the burn edges towards its center with incomplete re epithelialization [Figure 21].

The underlying granulation tissue showed numerous blood vessels, fibroblast and macrophages [Figure 22]. The newly formed epidermis appeared more or less normal with absence of skin appendages. The underlying granulation tissue was replaced by new dermal tissue. This dermis contained many dilated blood vessels, numerous mononuclear inflammatory cells and empty spaces. [Figure 23].

Masson trichrome stained sections showing the granulation tissue contained horizontally aligned, regularly arranged collagen fibers [Figure 24]. While the completely regenerated area showed fine and faintly stained collagen fibers superficially and bundles of thick collagen fibers deeply [Figure 25].

Immunohistochemical staining for VEGF showed moderate localized immunoreactivity is seen in some endothelial cells of dermal vessels. [Figure 26]. 

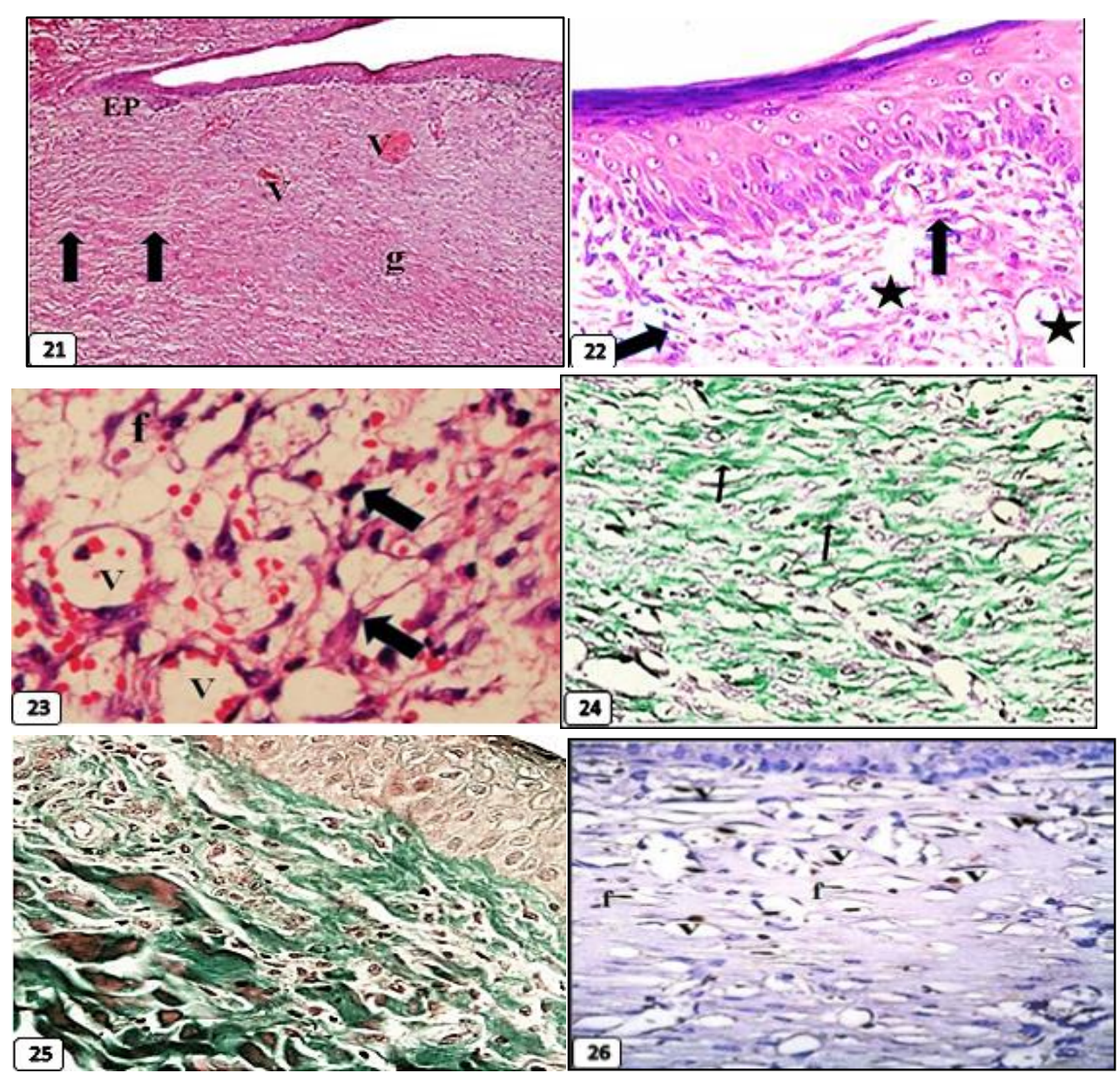

Figure [21]. A photomicrograph of a section of the burned skin 21days after burn induction showing the site of the healed burn and adjacent nearby normal skin with complete absence of the scab. The granulation tissue[g] is covered by newly formed epidermis, but the re-epithelialization [Ep] is not complete. The granulation tissue [g] shows collagen fibers deposition[arrows] and numerous blood vessels [v]. [Subgroup III.C: H and E; x 100]. Figure [22]. A photomicrograph of a section of the burned skin 21days after burn induction showing many blood vessels [V] fibroblasts [f] and macrophages[arrows] in the granulation tissue. [Subgroup III.C: $\mathrm{H}$ and E; $x$ 600]. Figure [23]. A photomicrograph of a section of the burned skin 21 days after burn induction showing the newly formed epithelium [Ep] with complete disappearance of scab. The epithelial cells appeared more or less normal. The dermis contained numerous blood vessels [v], mononuclear inflammatory cells [arrows]. No skin appendages can be detected. Notice: Empty spaces in the dermis[astrix]. [Subgroup III.C: H and E; x 400]. Figure [24].A photomicrograph of a section of the burned skin 21 days after burn induction showing the granulation tissue contains horizontally aligned, regularly arranged collagen fibers . [Subgroup III.C: Masson's trichrome; X400]. Figure [25]. A photomicrograph of a section of the burned skin 21 days after burn induction showing fine and faintly stained collagen fibers superficially and bundles of thick collagen fibers deeply. [Subgroup III.C: Masson's trichrome .X400]. Figure [26]. A photomicrograph of a section of the burned skin 21days after burn induction showing moderate localized immune reactivity is seen in blood vessels [v] and fibroblasts [f].[Subgroup III.C: Avidin-biotin peroxidase stain with Hx counter stain; $x$ 400]

iv- Group. IV:

\section{Subgroup. IVA:}

Light microscopic examination of hematoxylin and eosin stained sections of the burned skin7 days after intra dermal injection of BM stem cells revealed the presence of a thick scab covering the burn area. Beneath the scab there was an early growth of thickened epidermis over the edges of the burn [beginning of re-epithelialization] [Figure 27]. The newly formed granulation tissue proliferated to the same level of the adjacent nearby skin edges filling the burn area completely with areas of angiogenesis [Figure 27]. The granulation tissue showed numerous newly formed blood vessels, fibroblasts and macrophages [Figure 28]. Masson trichrome stained sections showed early deposition of newly 
formed thin deeply stained irregularly distributed collagen fibers was observed in the granulation tissue [Figure 29]. Immunohistochemical staining for VEGF showed widespread dense immunoreactivity in mononuclear cells, fibroblastic cells and endothelial cells of blood vessels [Figure 30].

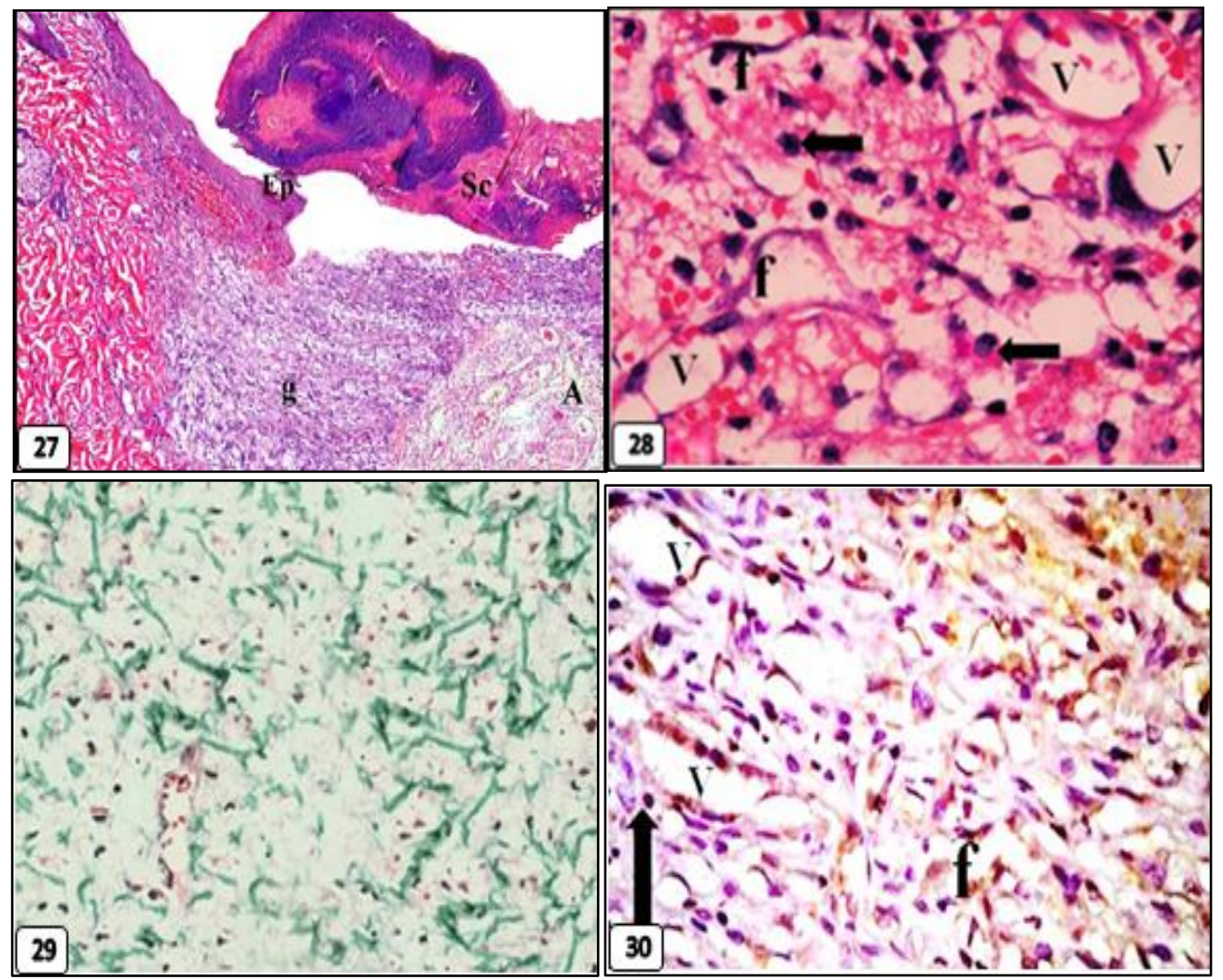

Figure [27]. A photomicrograph of a section of the burned skin7 days after intra dermal injection of BM stem cells showing the site of the burn and adjacent nearby normal skin. The wound area is covered by thick scab [Sc]. The epidermis [Ep] at the cut edge is thickened and the beginning of re-epithelialization at the burn area can be seen. The granulation tissue [g] is observed with an area of angiogenesis [A]. The underlying dermis of nearby skin is also noted. [Subgroup IV.A: $H$ and E; $x$ 100]. Figure [28]. A photomicrograph of a section of the burned skin7 days after intra dermal injection of BM stem cells showing that the granulation tissue is formed of newly formed blood vessels [V], numerous macrophages [arrows] and many fibroblasts [f ].[Subgroup IV.A: $\mathrm{H}$ and $\mathrm{E} ; \mathrm{x}$ 600]. Figure [29]. A photomicrograph of a section of the burned skin7 days after intra dermal injection of $B M$ stem cells showing that the granulation tissue at the site of burn is formed of deeply stained irregularly distributed collagen fibers in the granulation tissue [green color]. [Subgroup IV.A: Masson's trichrome .X400]. Figure [30].A photomicrograph of a section of the burned skin7 days after intra dermal injection of BM stem cells showing widespread dense immunoreactivity in mononuclear cells [arrows], fibroblastic cells [f] and endothelial cells of blood vessels[v].[Subgroup IV.A: Avidin-biotin peroxidase stain with $\mathrm{Hx}$ counter stain; $\mathrm{x} 400]$.

\section{Subgroup IV.B:}

Light microscopic examination of hematoxylin and eosin stained sections of the burned skin14 days after intra dermal injection of BM stem cells revealed newly formed epidermis and loss of the scab. The epidermis showed mature differentiation lying on straight basement membrane [Figure 31]. The epidermis was regularly arranged in four layers, stratum basal was formed of crowded low columnar basophilic cells with basal oval nuclei. Superficial to this layer, prickle cell layer consisted of few polyhedral acidophilic cells with central rounded nuclei. Cells of stratum granulosum were flattened with basophilic granular cytoplasm. Finally, the stratum corneum appeared to be formed of few acidophilic scales [Figure 32]. The underlying granulation tissue showed few inflammatory cell infiltrate, many blood vessels and fibroblasts with few macrophages [Figure 33]. Masson trichrome stained sections showed collagen fibers were aligned parallel to the surface. They were 
deposited in between and around the blood vessels [Figure 34]. Immunohistochemical staining for VEGF showed strong positive reaction in fibroblastic cells and endothelial cells of blood vessels [Figure 35].
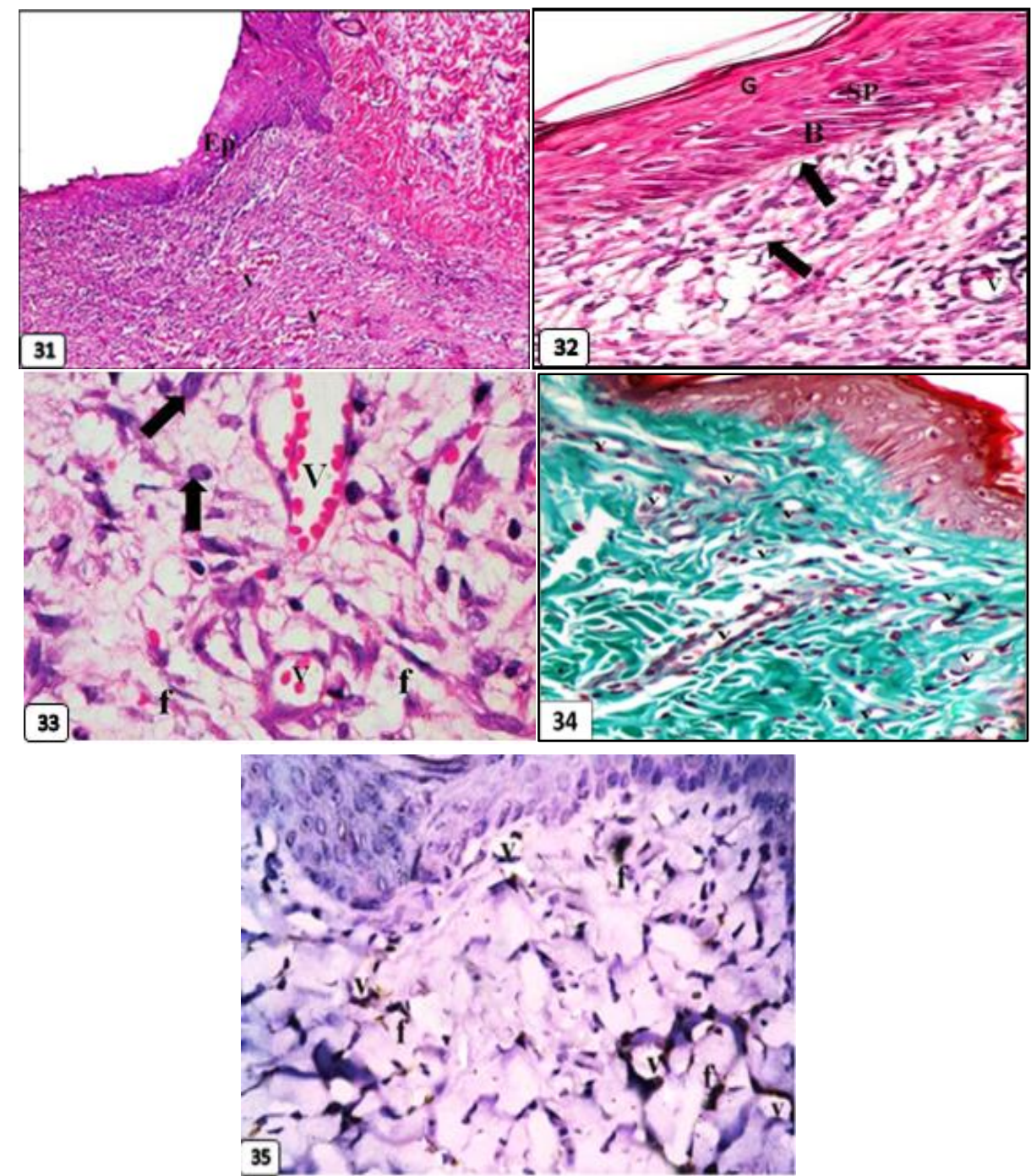

Figure [31]. A photomicrograph of a section of the burned skin14 days after intra dermal injection of BM stem cells showing loss of the scab, the newly formed epidermis [Ep] and the underlying granulation tissue [g] with numerous blood vessels [v]. [Subgroup IVB: H\&E x 100]. Figure [32]. A photomicrograph of a section of the burned skin14 days after intra dermal injection of BM stem cells showing regular arrangement of layers of newly formed epidermis; basal cell layer [B], stratum spinosum [Sp], granular cell layer [G] and the keratin on the top. Numerous blood vessels [V] and fibroblasts [arrows] can be noticed in the granulation tissue. [Subgroup IVB: H\&E x 400]. Figure [33]. A photomicrograph of a section of the burned skin14 days after intra dermal injection of BM stem cells at the site of the burn, showing many blood vessels [V] and fibroblasts [f] with few macrophages [arrows] in the granulation tissue. [Subgroup IV.B: H\&E x 600]. Figure [34]. A photomicrograph of a section of the burned skin14 days after intra dermal injection of BM stem cells at the site of the burn showing heavy deposition of collagen fibers [green coloration]. They were deposited in between and around the numerous blood vessels [V] [Subgroup IV.B: Masson trichrome $x$ 400]. Figure [35]. A photomicrograph of a section of the burned skin14 days after intra dermal injection of BM stem cells showing widespread dense immune reactivity in fibroblastic cells [f] and endothelial cells of blood vessels[v]. [Subgroup IV.B: Avidin-biotin peroxidase stain with Hx counter stain; x 400].

\section{Subgroup IV.C:}

Light microscopic examination of hematoxylin and eosin stained sections of the burned skin 21 days after intra dermal injection of BM stem cells showed complete re epithelialization of the epidermis which appeared as stratified squamous epithelium lying on a wavy basement membrane 
and covered with a layer of keratin [Figures 36 \& 37]. The epidermis was comparable to the control group. Prominent dermal-epidermal junction. The epidermis was composed of 4 layers. Stratum basale was formed of crowded low columnar basophilic cells with basal oval nuclei. Above this layer, stratum spinosum was present and consisted of few polyhedral acidophilic cells with central rounded nuclei. Many rounded cells with deeply stained nucleus that were surrounded by clear halo were present in the stratum spinosum probably non-keratinocytes [Langerhans cells]. Stratum granulosum consisted of 2 rows of spindle-shaped cells with basophilic granular cytoplasm. Finally, the stratum corneum appeared to be formed of few acidophilic scales [Figure 36]. $\mathrm{Re}$ appearance of hair follicles and sebaceous glands were noticed [Figures 36 and 37]. Masson trichrome stained sections showed thin collagen fibers beneath the epidermis forming the papillary dermis and the rest of the dermis showed thick wavy collagen bundles forming the reticular dermis [Figure 38]. Immunohistochemical staining for VEGF showed positive reaction in fibroblastic cells and endothelial cells of blood vessels [Figure 39].

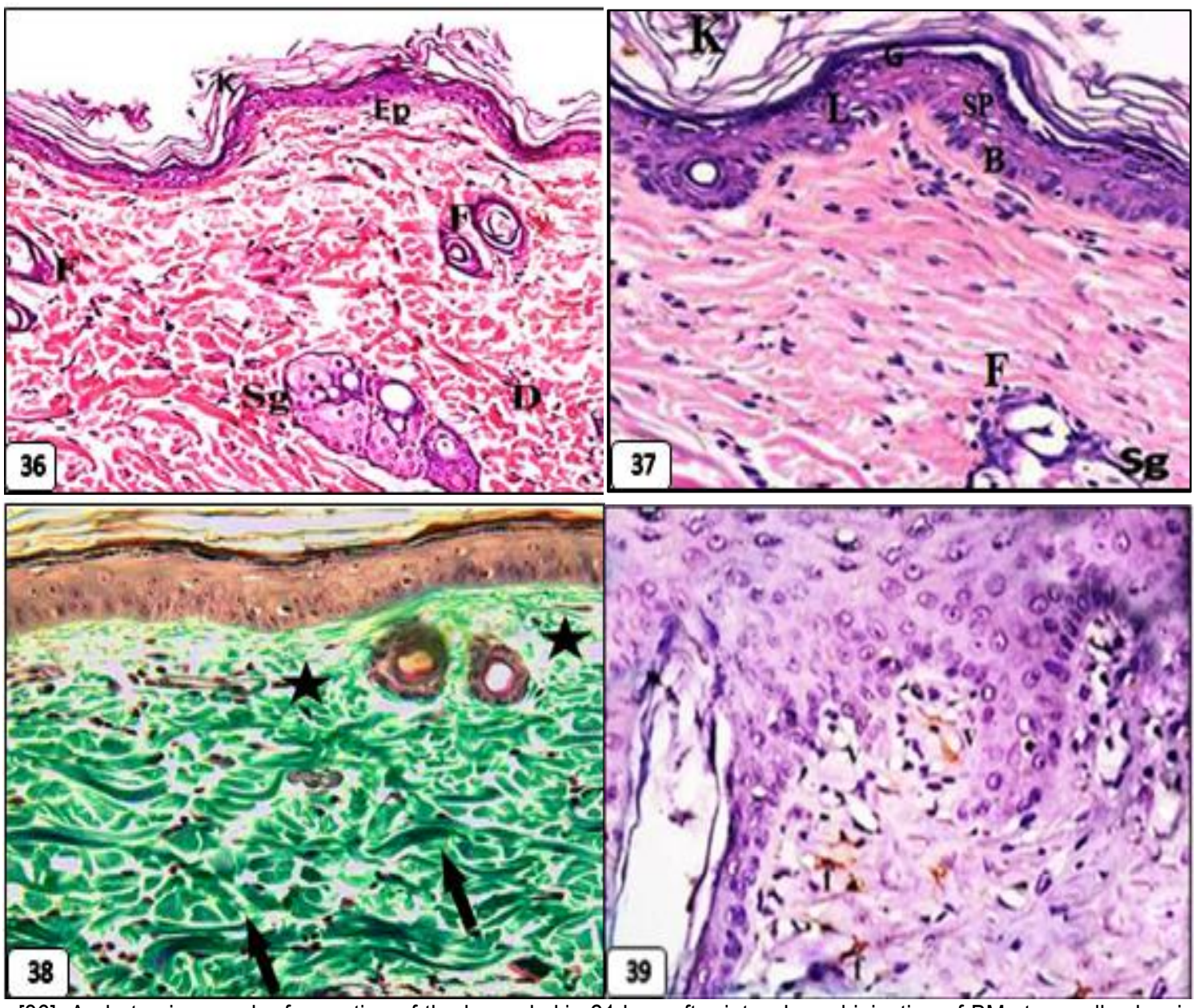

Figure [36]. A photomicrograph of a section of the burned skin 21days after intra dermal injection of BM stem cells showing apparently normal epidermis lined with keratinized stratified squamous epithelium [arrow] lying on a wavy basement membrane and dermis[D]. Sebaceous glands [Sp] and hair follicles [F] are seen in the dermis. [Subgroup IV.C: H\&E x 100]. Figure [37]A photomicrograph of a section of the burned skin 21 days after intra dermal injection of BM stem cells showing normal epidermis formed of stratum basale [B], 2-3 layers of stratum spinosum [Sp] Langerhans cell[L], 2-3 layers of stratum granulosum [G] and keratin [K]. Prominent dermal-epidermal junction [astrix]. Notice: hair follicle [F] appear in the dermis [Subgroup IV.C: H\&E $x$ 400]. Figure [38]. A photomicrograph of a section of the burned skin 21days after intra dermal injection of BM stem cells showing' the papillary dermis containing fine collagen fibers [astrix] and the reticular dermis is filled with thick wavy collagen bundles [arrows]. [Subgroup IV.C: Masson trichrome x 400]. Figure [39]. A photomicrograph of a section of the burned skin 21days after intra dermal injection of BM stem cells showing localized immune reactivity in the fibroblastic cells [f] and endothelial cells of blood vessels[v]. Subgroup. IV.C: Avidin-biotin peroxidase stain with Hx counter stain; x 400]. 
v- Group V:

\section{Subgroup V.A:}

Light microscopic examination of hematoxylin and eosin stained sections of the burned skin7 days after intra peritoneal injection of BM stem cells revealed the presence of a thick scab covering the burn area [Figure 40]. The creeping epithelium were noticed at the edge of the burned area, the granulation tissue partially fills the burn gap and showed newly formed blood vessels
[Figure 40]. Fibroblasts, polymorph nuclear cells and many macrophages were also noted [Figure 41]. Masson trichrome stained sections showed early deposition of newly formed thin deeply stained irregularly distributed collagen fibers was observed in the granulation tissue [Figure 42]. Immunohistochemical staining for VEGF revealed widespread dense immunoreactivity in perivascular mononuclear cells, fibroblastic cells and endothelial cells of blood vessels [Figure 43].

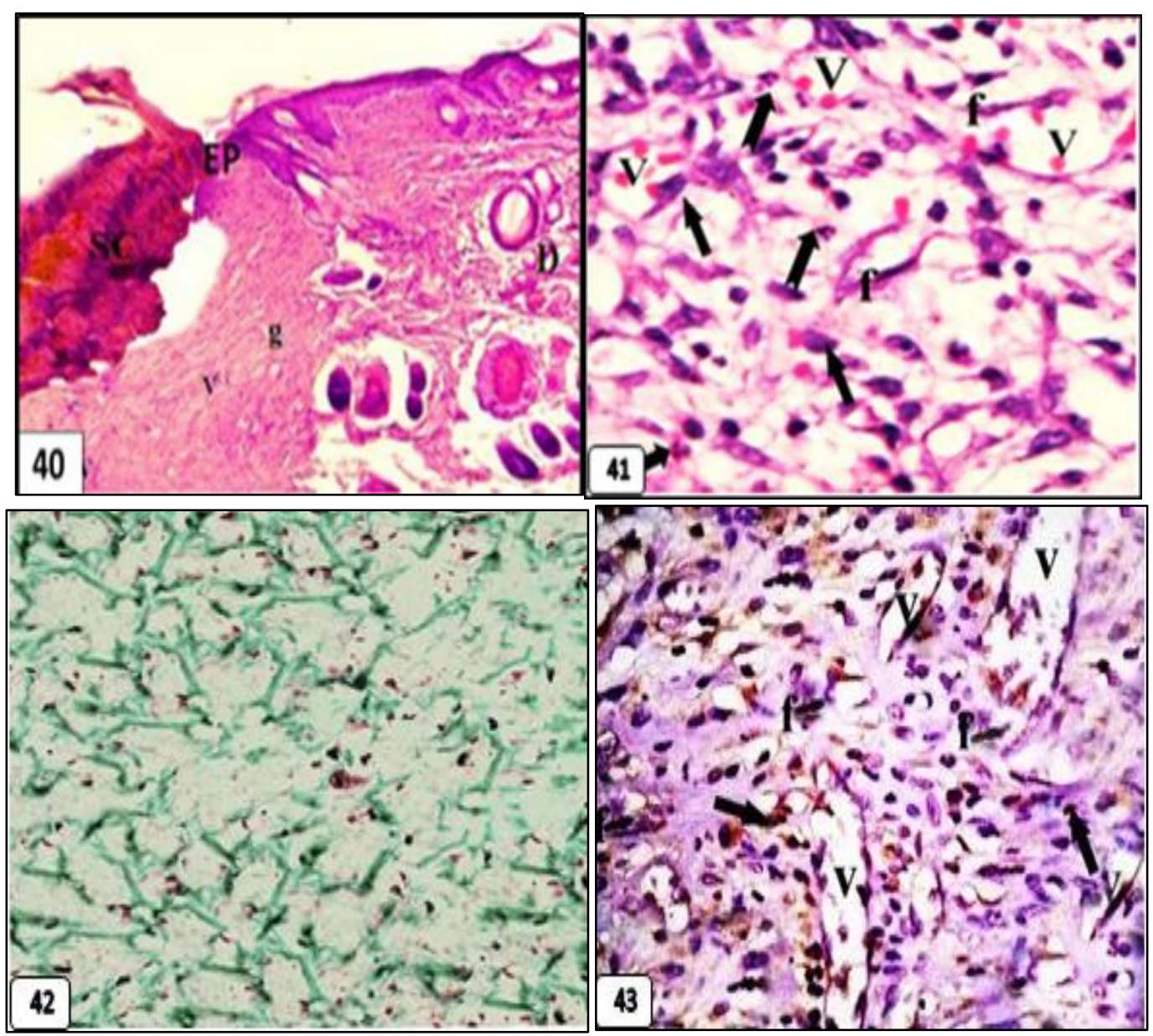

Figure [40]. A photomicrograph of a section of the burned skin 7days after intra peritoneal injection of BM stem cells showing the site of the burn and adjacent nearby normal skin. The burn area is covered by thick scab [Sc] that overlies the newly formed granulation tissue [g] containing newly formed blood vessels [v]. The nearby skin shows the epidermis [Ep] and dermis [D]. Note the creeping epithelium at the edge of the burned area [arrow] [Subgroup V.A: H\&E x 100]. Figure [41].A photomicrograph of a section of the burned skin 7days after intra peritoneal injection of BM stem cells showing that the granulation tissue contains polymorphonuclear cells [notched arrows], many macrophages [arrows], fibroblasts [f] and multiple blood vessels [V].[Subgroup V.A: H\&E x 600]. Figure [42]. A photomicrograph of a section of the burned skin 7days after intra peritoneal injection of $B M$ stem cells showing that the granulation tissue at the site of burn is formed of deeply stained irregularly distributed collagen fibers in the granulation tissue [green coloration].[Subgroup V.A: Masson trichrome x 400]. Figure [43].A photomicrograph of a section of the burned skin 7days after intra peritoneal injection of BM stem cells showing widespread dense immunoreactivity in perivascular mononuclear cells [arrows], fibroblast [f] and endothelial cells of blood vessel[v].[Subgroup V.A: Avidin-biotin peroxidase stain with Hx counter stain; x 400]. 
Abd Allah FM, et al.

\section{Subgroup V.B:}

Light microscopic examination of hematoxylin and eosin stained sections of the burned skin14 days after intra peritoneal injection of BM stem cells revealed newly formed epidermis lying on a straight basement membrane [Figure 44] and loss of the scab. The epidermis was regularly arranged in four layers, stratum basal was formed of crowded low columnar basophilic cells with basal oval nuclei. Superficial to this layer, stratum spinosum consisted of few polyhedral acidophilic cells with central rounded nuclei. Cells of stratum granulosum were flattened with basophilic granular cytoplasm. Finally, the stratum corneum appeared to be formed of few acidophilic scales [Figure 45].

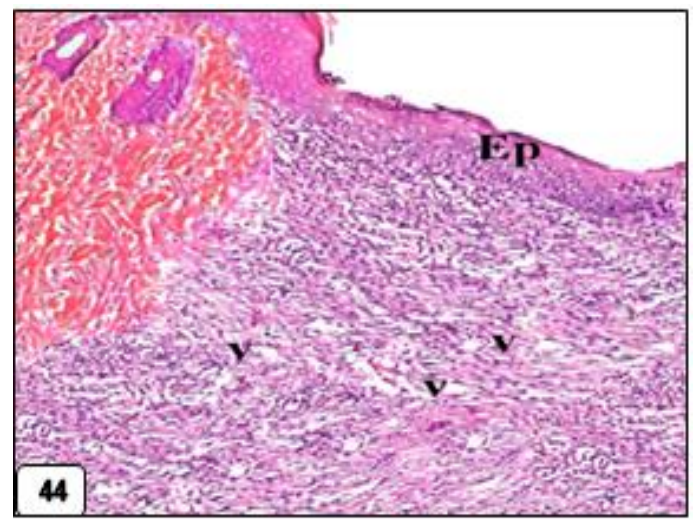

Figure [44].A photomicrograph of a section of the burned skin 14 days after intra peritoneal injection of BM stem cell showing loss of the scab, the newly formed epidermis [Ep] and the underlying granulation tissue with numerous blood vessels [v]. [Subgroup V.B: H\&E x 100].

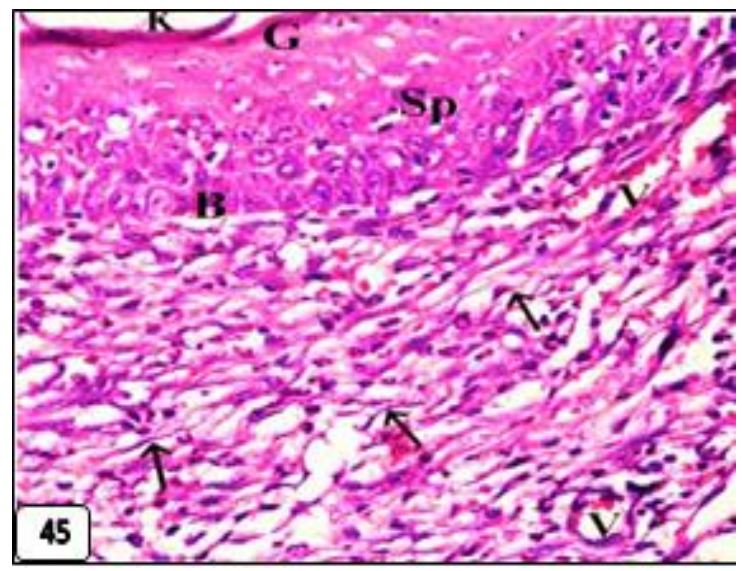

Figure [45]. A photomicrograph of a section of the burned skin 14 days after intra peritoneal injection of BM stem cells showing regular arrangement of layers of newly formed epidermis; basal cell layer $[B]$, stratum spinosum [Sp] granular cell layer [G]. Blood vessels [V] and fibroblasts [arrows] can be noticed in the granulation tissue. [Subgroup V.B: H\&E x 400].
The underlying granulation tissue showed few inflammatory cell infiltrate, many blood vessels and fibroblasts with few macro-phages [Figure 46].

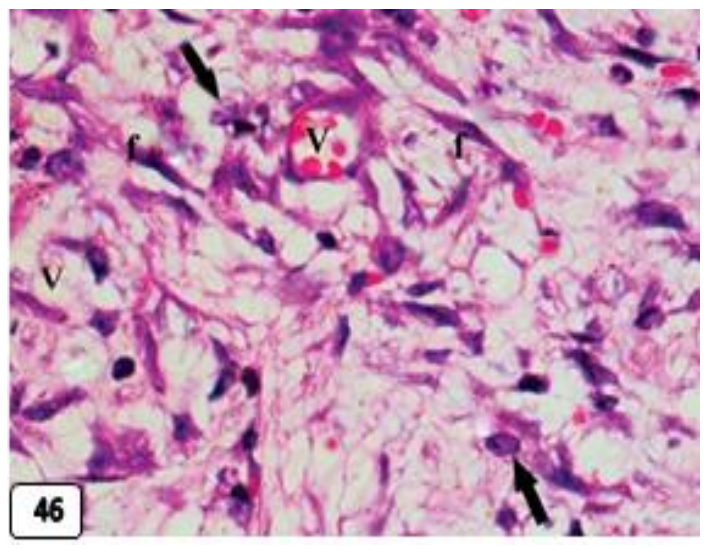

Figure [46] A photomicrograph of a section of the burned skin14 days after intra dermal injection of BM stem cells at the site of the burn, showing many blood vessels [V] and fibroblasts [f] with few macrophages [arrows] in the granulation tissue. [Subgroup IV.B: $\mathrm{H} \& \mathrm{E} \times 600]$.

Masson trichrome stained sections showed collagen fibers were aligned parallel to the surface. They were deposited in between and around the blood vessels [Figure 47].

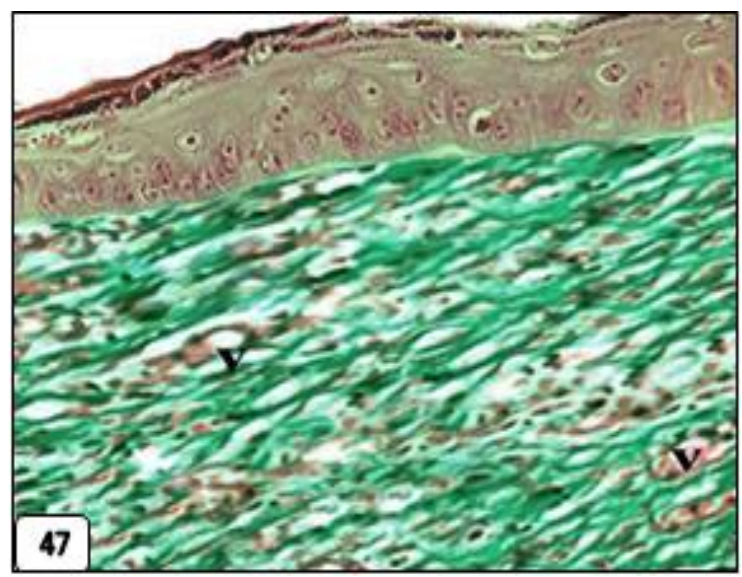

Figure [47]. A photomicrograph of a section of the burned skin 14 days after intra peritoneal injection of BM stem cells showing collagen fibers were aligned parallel to the surface. They were deposited in between and around the blood vessels.[Subgroup V.B: Masson trichrome $x$ 400].

Immunohistochemical staining for VEGF showed strong positive reaction in fibroblastic cells and endothelial cells of blood vessels [Figure 48]. 


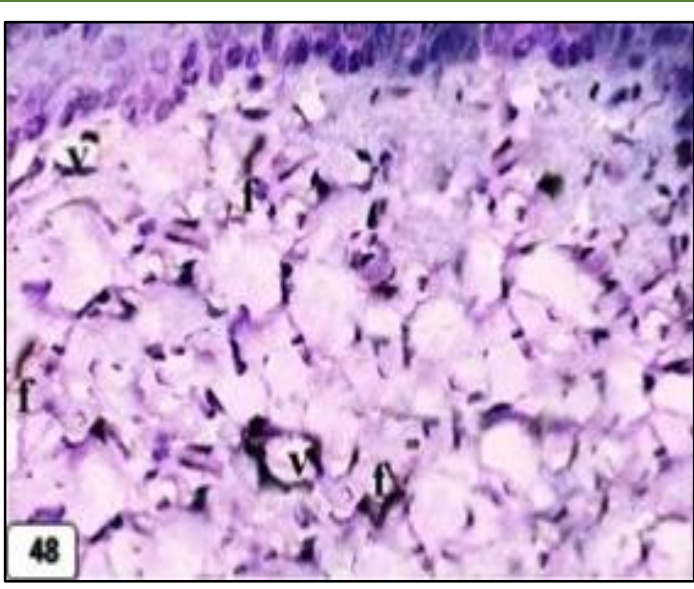

Figure [48]. A photomicrograph of a section of the burned skin 14 days after intra peritoneal injection of BM stem cells showing widespread dense immune reactivity in fibroblastic cells [f] and endothelial cells of blood vessels[v]. [Subgroup V.B: Avidin-biotin peroxidase stain with $\mathrm{Hx}$ counter stain; $\mathrm{x} 400$ ].

\section{Subgroup V.C:}

Light microscopic examination of hematoxylin and eosin stained sections of the burned skin 21 days after intra peritoneal injection of BM stem cells showed complete re epithelization of the epidermis which appeared as stratified squamous epithelium resting on a wavy basement membrane and covered with a layer of keratin [Figure 49].

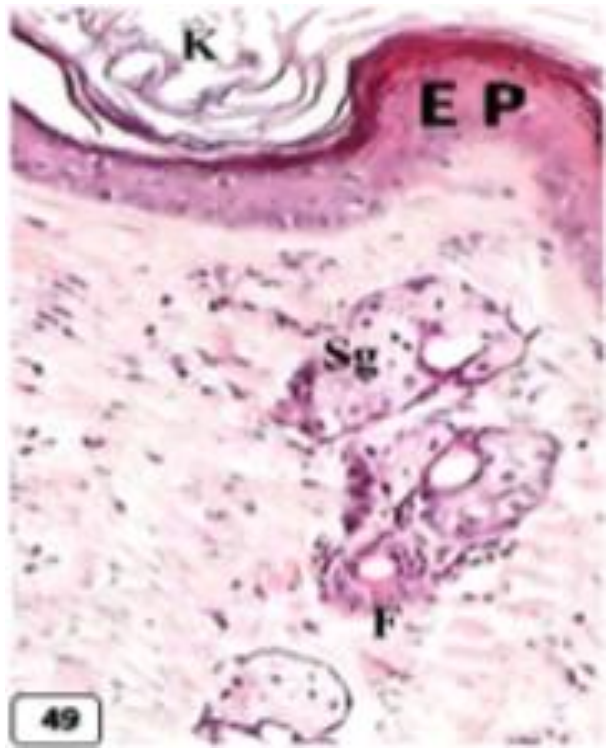

Figure [49]. A photomicrograph of a section of the burned skin 21days after intra peritoneal injection of BM stem cells showing apparently normal epidermis lined with stratified squamous epithelium [Ep] lying on a wavy basement membrane and covered with keratin $[\mathrm{K}]$. Sebaceous gland $[\mathrm{Sg}]$ and hair follicles $[\mathrm{F}]$ are seen in the dermis. [Subgroup V.C: H\&E x 100].
The epidermis was comparable to the control group. The epidermis was formed of 4 layers. Stratum basale was formed of crowded low columnar basophilic cells with basal oval nuclei. Above this layer, stratum spinosum was present and consisted of few polyhedral acidophilic cells with central rounded nuclei. Many rounded cells with deeply stained nucleus that were surrounded by clear halo were present in the stratum spinosum probably non-keratinocytes [Langerhans cells]. Stratum granulosum consisted of 2 rows of spindle-shaped cells with basophilic granular cytoplasm. Finally, the stratum corneum appeared to be formed of few acidophilic scales [Figure 50].

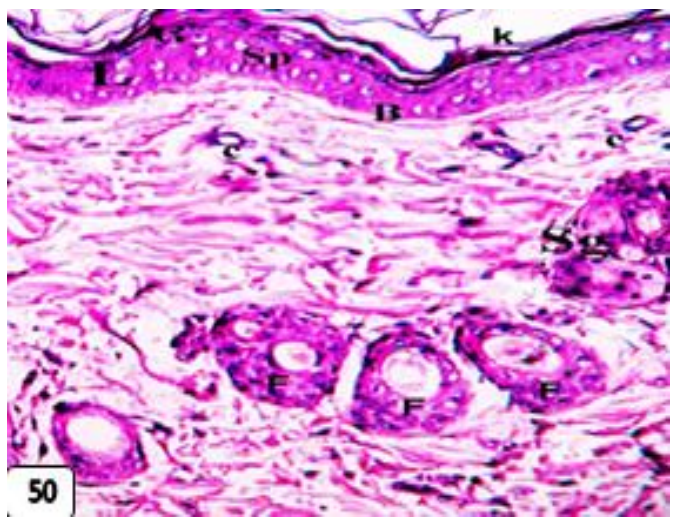

Figure [50]. A photomicrograph of a section of the burned skin 21days after intra peritoneal injection of BM stem cells showing normal epidermis formed of stratum basale $[B], 2-3$ layers of stratum spinosum [SP], Langerhans cell [arrow] 2-3 layers of stratum granulosum $[\mathrm{G}]$ and keratin $[\mathrm{K}]$. Prominent dermalepidermal junction [astrix] and numerous patent blood capillaries [c] surrounded by inflammatory cells in papillary layer are seen. Sebaceous gland $[S]$ and hair follicles [F] are seen in the dermis. [Subgroup V.C: H\&E x 400].

In the papillary dermis, numerous patent blood vessels surrounded by inflammatory cells were seen [Figure 51]. It also showed the reappearance of multiple hair follicles and sebaceous glands [Figures 50\&51]. Delayed wound healing with inflammatory cell infiltrate, few congested blood vessels, no hair follicles and sebaceous glands were seen only in $20 \%$ of this group [Figure 51 ]. Masson trichrome stained sections showed thin collagen fibers under the epidermis forming the papillary dermis while the reticular dermis revealed thick wavy collagen bundles [Figure 52].Delayed wound healing revealed dense collagen bundles formed of thin fibres; most of them are arranged in parallel direction gland were 
seen only in $20 \%$ of this group [Figure 53]. Immunohistochemical staining for VEGF revealed showed positive reaction in fibroblastic cells and endothelial cells of blood vessels [Figure 54].
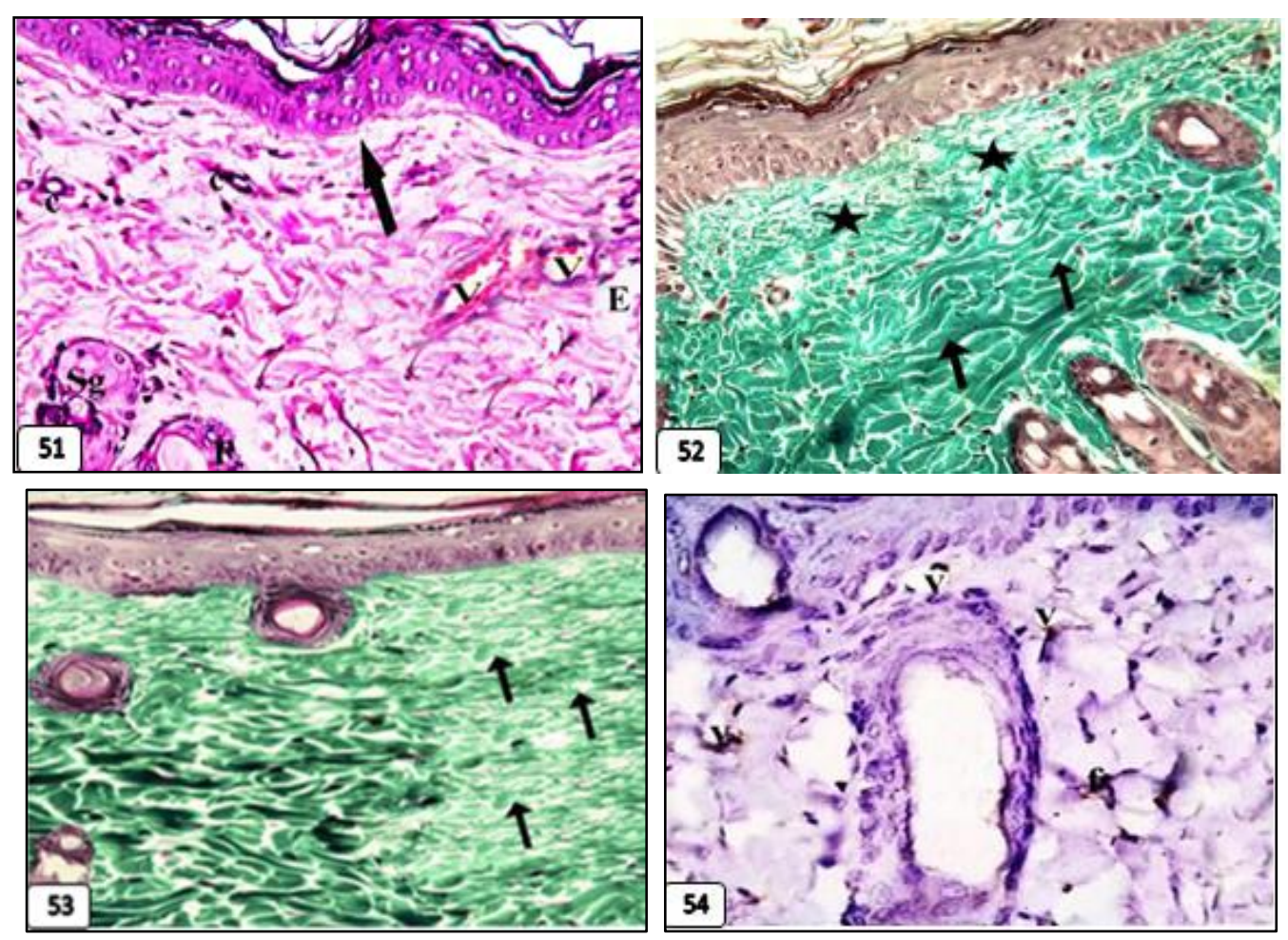

Figure [51]. A photomicrograph of a section of the burned skin 21days after intra peritoneal injection of BM stem cells showing the junction between healed wound and delayed healing wound area [ arrow]. Delayed healing area shows few congested blood vessels surrounded by inflammatory infiltrate [astrix], empty spaces[E], absent hair follicles and sebaceous glands. [Subgroup V.C: H\&E x 400]. Figure [52]A photomicrograph of a section of the burned skin 21days after intra peritoneal injection of BM stem cells showing the papillary dermis containing fine collagen fibers [astrix] and the reticular dermis is filled with thick wavy collagen bundles [arrows]. [Subgroup V.C: Masson trichrome $x$ 400]. Figure [53] A photomicrograph of a section of the burned skin 21days after intra peritoneal injection of BM stem cells showing the junction between healed wound and delayed healing wound area. Delayed healing wound shows dense collagen bundles formed of thin fibres; most of them are arranged in parallel direction[arrows]. [Subgroup V.C: Masson trichrome $x$ 400]. Figure [54]. A photomicrograph of a section of the burned skin 21 days after intra peritoneal injection of BM stem cells showing localized immune reactivity in the fibroblastic cells [f] and endothelial cells of blood vessels[v]. [Subgroup V.C: Avidin-biotin peroxidase stain with Hx counter stain; $x$ 400].

\section{Statistical results:}

\section{A. Blood vessels count:}

By studying the mean values of area among all rats of the experimental group, it was found that the mean value of the blood vessels counts recorded in group. I [control] was [14.83] then followed by decrease in group. II [burn model] [10.33]. By studying the mean values of the blood vessels count/[um]surface among all rats of groups III, IV \&V on day7 post burning ,it was found that the highest mean value of the blood vessel count were recorded in subgroups IV.A [29.67] \& V.A [27.60] in comparison to the sub group III.A[21.33] . After 14 days post-burning, the highest mean values of the blood vessels count were recorded in subgroups IV.B [40] \&V. B [38] in comparison to the sub group III.B [28.17].

On day 21 post-burning, the highest mean values of the blood vessels count were recorded in sub group III.C [18.5] in comparison to sub groups IV.C [14.67] \&V.C [13.69]. All of these values were of statistically significant difference [p<0.05] [Table: 1].

\section{B. Macrophage count:}

By studying the mean values of the macrophage count/[um]surface area among all rats of groups III, IV \&V on day7 post burning ,it was found that the highest mean value of the macrophage count were recorded in subgroups IV.A[23.5]\&V.A [22.5] in comparison to the sub 
group III.A[19.17] . After 14 days post-burning, the highest mean values of the macrophage count were recorded in subgroups IV.B [18.17] \& V. B [17.27] in comparison to sub group III.B[17]. On day 21 post-burning, the highest mean value of the macrophage count was recorded in sub group III.C [12.67] in comparison to sub groups IV.C[9.17] \&V.C [8.67]. All of these values were of statistically significant difference $[p<0.05]$ [Table:2].

\section{Fibroblast count:}

By studying the mean values of the fibroblast count/[um]surface area among all rats of groups III, IV \&V on day7 post burning, it was found that the highest mean value of the fibro blast count were recorded in subgroups IV.A [27.33] \&V.A [25.5] in comparison to the sub group III.A[5.67]. After 14 days post-burning, the highest mean values of the fibroblast count were recorded in subgroups IV.B [27.33] \& V.B [26.33] in comparison to the sub group III.B[19.22]. On day 21 post-burning, the mean values of the fibro blast count decreased in sub groups IV.C [18.33] \&V.C [18.67] in comparison to the sub group III.C[22].

All of these values were of statistically significant difference [ $p<0.05]$ [Table 3].

\section{Mean area percent of collagen fibers:}

By studying the mean values of collagen fibers density among all rats of the experimental group, it was found that the mean value collagen fibers density recorded in group. I [control] was [ 31.96] then followed by decrease in group.II [burn model] [12.13].

On day7 post burning, it was found that the highest mean value of collagen fibers density was recorded in subgroups IV.A [22.78] \& V.A [21.14] in comparison to the sub group III.A [17.32].

After 14 days post-burning, the highest mean values were recorded in subgroups IV.B [29.33] \& V. B [28.48] followed by sub group III.B[28.17].

On day 21 post-burning, the highest mean values of the blood vessels count decreased in sub groups IV.C [34.29] \&V.C [32.79] in comparison to the sub group III.C [30.78]. All of these values were of statistically significant difference $[p<0.05]$ [Table:4].

\section{E. Mean area percent of VEGF immune positive cells:}

By studying the mean values of VEGF immune positive cells density among all rats of the experimental group, it was found that the mean value of VEGF immune positive cells density recorded in group. I [control] was [ 70.18]. On day7 post burning, it was found that the highest mean values of VEGF immune positive cells density were recorded in subgroups IV.A[13.5] \& V.A [12.43] in comparison to the sub group III.A [7.3] .

After 14 days post-burning, the highest mean values VEGF immune positive cells density was recorded in subgroups IV.B [62.34] \& V. B [61.7] in comparison to sub group III.B[54.36].

On day 21 post-burning, the highest mean values of VEGF immune positive cells density were recorded in sub groups IV.C[65.45] \&V.C [64.96] in comparison to the sub group III.C [61.47]. All of these values were of statistically significant difference $[p<0.05]$ [Table:5].

Table [1]: Comparison of the number of blood vessels / high power field [x100] in the skin of the experimental groups

\begin{tabular}{|l|c|c|c|c|}
\hline \multicolumn{1}{|c|}{ Post-burning days } & Groups & Mean & \pm SD & P value \\
\hline \multirow{3}{*}{ Day 7 } & Subgroup III.A & 21.33 & \pm 2.42 & \\
\cline { 2 - 5 } & Subgroup IV.A & 29.67 & \pm 3.39 & 0.0174 \\
\cline { 2 - 5 } & Subgroup V.A & 27.60 & \pm 3.37 & 0.0164 \\
\hline \multirow{3}{*}{ Day 14 } & Subgroup III.B & 28.17 & \pm 2.64 & \\
\cline { 2 - 5 } & Subgroup IV.B & 40 & \pm 2.61 & 0.000 \\
\cline { 2 - 5 } Day 21 & Subgroup V.B & 38 & \pm 2.59 & 0.0474 \\
\cline { 2 - 5 } & Subgroup III.C & 18.5 & \pm 4.04 & 0.002 \\
\cline { 2 - 5 } & Subgroup IV.C & 14.67 & \pm 3.56 & 0.016 \\
\cline { 2 - 5 } & Subgroup V.C & 13.69 & \pm 3.53 & 0 \\
\hline
\end{tabular}


Abd Allah FM, et al.

Table [2]: Comparison of the number of Macrophage count / high power field [x600] in the skin of the experimental groups

\begin{tabular}{|c|c|c|c|c|}
\hline \multirow{3}{*}{ Post-burning days } & Groups & Mean & \pm SD & P value \\
\hline \multirow{3}{*}{ Day 7 } & Subgroup III.A & 5.67 & \pm 1.86 & \\
\cline { 2 - 5 } & Subgroup IV.A & 27.33 & \pm 1.97 & 0.0076 \\
\cline { 2 - 5 } & Subgroup V.A & 25.5 & \pm 1.93 & 0.0170 \\
\hline \multirow{3}{*}{ Day 21 } & Subgroup III.B & 19.22 & \pm 1.966 & \\
\cline { 2 - 5 } & Subgroup IV.B & 27.33 & \pm 1.966 & 0.01940 \\
\cline { 2 - 5 } & Subgroup V.B & 26.33 & \pm 1.876 & 0.0384 \\
\cline { 2 - 5 } & Subgroup III.C & 22 & \pm 4.38 & \\
\cline { 2 - 5 } & Subgroup IV.C & 18.83 & \pm 2.68 & 0.003 \\
\cline { 2 - 5 } & Subgroup V.C & 18.67 & \pm 2.64 & 0.0021 \\
\hline
\end{tabular}

Table [3]: Comparison of the number of fibroblasts / high power field [x600] in the skin of the experimental groups

\begin{tabular}{|c|c|c|c|c|}
\hline Post-burning days & Groups & Mean & \pm SD & P value \\
\hline \multirow{3}{*}{ Day 7 } & Subgroup III.A & 31.96 & \pm 4.52 & \\
\cline { 2 - 5 } & Subgroup IV.A & 12.31 & \pm 3.49 & 0.0231 \\
\cline { 2 - 5 } & Subgroup V.A & 17.32 & \pm 0.66 & 0.0002 \\
\hline \multirow{3}{*}{ Day 14 } & Subgroup III.B & 22.78 & \pm 1.37 & \\
\hline \multirow{3}{*}{ Day 21 } & Subgroup IV.B & 21.14 & \pm 1.29 & 0.0214 \\
\cline { 2 - 5 } & Subgroup V.B & 22.46 & \pm 1.47 & 0.0164 \\
\cline { 2 - 5 } & Subgroup III.C & 29.23 & \pm 3.53 & \\
\cline { 2 - 5 } & Subgroup IV.C & 28.48 & \pm 3.50 & 0.000 \\
\cline { 2 - 5 } & Subgroup V.C & 30.78 & \pm 1.76 & 0.0020 \\
\hline
\end{tabular}

Table [4]: Comparison of the mean values of the area density percentage of collagen fibers / high power field [ $\mathrm{x} 400]$ in the skin of the experimental groups

\begin{tabular}{|l|c|c|c|c|}
\hline \multicolumn{1}{|c|}{ Post-burning days } & Groups & Mean & \pm SD & P value \\
\hline \multirow{3}{*}{$\begin{array}{l}\text { Day 7 } \\
\text { Post-burning }\end{array}$} & Subgroup III.A & 31.96 & \pm 4.52 & \\
\cline { 2 - 5 } & Subgroup IV.A & 12.31 & \pm 3.49 & 0.0231 \\
\cline { 2 - 5 } & Subgroup V.A & 17.32 & \pm 0.66 & 0.0002 \\
\hline \multirow{3}{*}{ Day 14 Post-burning } & Subgroup III.B & 22.78 & \pm 1.37 & \\
\cline { 2 - 5 } & Subgroup IV.B & 21.14 & \pm 1.29 & 0.0214 \\
\cline { 2 - 5 } & Subgroup V.B & 22.46 & \pm 1.47 & 0.0164 \\
\hline \multirow{3}{*}{ Day 21 Post-burning } & Subgroup II.C & 29.23 & \pm 3.53 & \\
\cline { 2 - 5 } & Subgroup IV.C & 28.48 & \pm 3.50 & 0.000 \\
\cline { 2 - 5 } & Subgroup V.C & 30.78 & \pm 1.76 & 0.0020 \\
\hline
\end{tabular}

\section{DISCUSSION}

Burns are a serious public health problem globally, accounting for an estimated 265000 deaths annually. Non-fatal burns cause disability and disfigurement, which can lead to physical, psychological, and economic difficulties [13].

Normal burn healing is a dynamic and complex process involving a variety of coordinated events, including bleeding and coagulation, acute inflammation, cell migration, proliferation, differentiation, angiogenesis, reepithelialization, \& extracellular matrix synthesis and remodeling ${ }^{[14]}$.
Several factors may impair healing of burned wound, including infection, tissue hypoxia, necrosis, exudates, and excess levels of inflammatory cytokines, prolonging one or more phases of inflammation, proliferation, or remodeling [15].

The goal of skin burn treatment is the enhancement of burn closure and restoration of skin function with good cosmetic results[ ${ }^{[16]}$.

The application of stem cell therapy is at the forefront of regenerative medicine in all medical fields. They are of special interest in burn wounds, as they have multiple potential indications for application; including - accelerating wound healing, enhancing skin regeneration to incorporate skin 
appendages, reducing fibrosis and improving scarring[17].

In this study, we tried to find out the histological effects of BM. MSCs on the healing of induced deep second-degree skin burn in adult male albino rats using both methods of stem cell injection; intra dermal and intra peritoneal. In the present study, 24 hours after culturing rat BM-MSCs, they appeared variable in size, shape, and arrangement. These findings coincided with Attia et al. [18] who found that after 24 hours from the culture of rat BMMSCs, many of them were rounded and spindleshaped and had attached to the bottom of the tissue culture flask.

On day 5 of primary culture of rat bone marrow cells, most of them continued to remain rounded and to be arranged in chains or to form colonies, while others appeared to be elongated and spindleshaped. Nine days after the primary culture in the current study, BM-MSCs became well-defined spindle-shaped fibroblast-like cells with processes. In the current work, 12 days after the primary culture, BM-MSCs appeared closely aggregated spindle-shaped cells with $80 \%$ confluency.

This finding came in agreement with Ghabrial et al. [19] who noticed heterogeneous population of large flattened, spindle shaped cells that appeared in the early days of the primary cultures of BMMSCs.

In the current study, deep second-degree skin burns injury of rats in groups II, III, IV and V were created by brass probe. The induced burn represents 1.1 TBSA $\%$ in the back to avoid shock and death of rats. This came in accordance with Pereira et al. [20] who stated that burns when reaching $26 \%$ to $30 \%$ TBSA [the whole back surface area] caused high mortality rates. Throughout the experiment, the naked eye observation was a greyish white area in the skin with exfoliated parts immediately after burn induction with redness around it [Group. II].

A brown scab was formed at the $7^{\text {th }}$ day [subgroup III.A] and still present to 14th day [subgroup III.B]. This came in agreement with Ahmed et al. [21] who noticed that in induced full thickness burn in albino rats, the scalded skin area was pale and edematous. They added that on the $7^{\text {th }}$ day after scalding, a scab appeared on the scalded area and still present till $14^{\text {th }}$ day post burn.

Twenty-one days after burn induction [subgroup III.C], the scab was separated leaving granulation tissue underneath and no healing was detected; while the adjacent small area show spontaneous healing. This came in agreement with Ahmed et al. [21] who stated that 21 days after SSD application in full thickness burn, the scab was separated leaving friable red granulation tissue.

This also goes with Johnson and Richard [22] study who stated that the time required for complete healing of deep second-degree burns, without the application of specific therapeutic agents, could be up to six weeks or more, leaving a scar tissue that may hypertrophy and contract itself.

In group. IV and group. V [BM-MSCs treated group], 7 days after MSCs injection, the burned area appeared covered with thick scab. Fourteen days after MSCs injection, the burned area appeared smaller and reddish in color with loss of the scab. These came in accordance with, Basiouny et al. ${ }^{[12]}$ who observed that thick scab covers the full thickness wounded skin at one week then became absent at 2 weeks after MSCs injection. However, the previous findings dis- agreed with Ahmed et al. ${ }^{[21]}$ who stated that there was no scab formation and the wound was pliable and softer in 7 days of BM-MSCs transplantation in burned rats.

The burned area 21 days after MSCs injection was markedly smaller and showed healing represented in coverage by epidermis with hair regrowth around it. This result came in agreement with Yang et al. [23] \& Ahmed et al. [21] who reported that on the $21^{\text {st }}$ day after MSCs transplantation, the burn wounds showed complete healing.

Delayed healing was seen in small parts of the burn in subgroup V.C. These came in accordance with, Basiouny et al. [12] who observed that on the $21^{\text {st }}$ day after MSCs injection, the burn wounds showed complete healing with complete regaining of hair was achieved in all animals of topically treated rats and in 4 out of 5 rats of systemically treated group. Examination of group. II [burn model] sections stained by $\mathrm{H} \& \mathrm{E}$ showed a range of 
epidermal thinning, necrosis or exfoliation. This came in agreement with Yang et al. [23] who found that the skin epidermis in deep second-degree burns was almost entirely dissected from the underlying dermis.

In the present study, the underlying dermis showed collagen degeneration in the form of fused and closely packed collagen fibers. Similarly, Heredero et al. [24] detected in their experimental burn model collagen degeneration at the papillary dermis. Also Park et al. [25] noticed that when the skin was thermally damaged, [dense coagulations of collagen].

Moreover, Tanaka et al. [26] detected loss of boundaries between collagen fibers and attributed this to water leakage from capillaries causing edema and fusion of collagen fibers. Masson trichrome stained sections of group. II [burn model group] showed denaturated collagen in the dermis. The collagen was stained red instead of green for healthy collagen. This came in accordance with Ahmed et al. [21] detection. Similarly, Xiao et al. [27] stated that Masson trichrome staining was a good indicator of burn wound depth and the red stain intensity reflected the tissue necrosis boundary.

In the present study, the hair follicles with their associated glands were damaged with loss of architecture in group II. This finding was also detected by Younan et al. [28]. However, Yang et al. [23] found a few residual hair follicles while the sebaceous glands showed structural damage.

In the current study, the burn model group [group II], no blood vessels were detected in the upper dermis of this group by H\&E stain. This came in accordance with Yang et al. ${ }^{23]}$ who observed that within the necrotic burn zone, there were no intact vascular structures. These findings were confirmed by immunohistochemically stained sections of group. II which exhibited negative immunoreaction for VEGF as blood vessels were not encountered through the examination of the upper part of the dermis. This was explained by Arno et al. [29] who stated that under normal circumstances, injury stimulated the proliferation of endothelial cells, but some severe harmful stimuli such as burns often lead to inhibition of endothelial cell proliferation and increased apoptosis. In the current study, H\&E stained sections from subgroup III.A showed presence of a scab with loss of epidermis. Also, damaged hair follicles with associated sebaceous glands was observed. These findings coincided with Fahimi et al. [30] studies on burn wound models.

Similarly, Yaman et al. ${ }^{[31]}$ observed the presence of crust formed by remnants of necrotic tissue.

Also, Sharma and John [32], indicated that the cell membranes release strong vasoconstrictors such as prostaglandin 2 alpha and thromboxane A2 immediately after the acute injury. The collagen in the wound began the cascade of the clotting. Collagen, thrombin and fibronectin are present in the resulting fibrin clot. These results in the release of inflammatory cytokines and growth factors such as interleukin-1[IL-1], tumor necrosis factor alpha [TNF- $\alpha$ ], transforming growth factor beta [TGF- $\beta$ ], platelet factor-4 which help in getting rid of the devitalized wound tissue.

In the current study, the granulation tissue in the burned area on day 7 post-burning burn included cellular elements [polymorphnuclear cells, fibroblasts and macrophages], new small blood vessels [angiogenesis] and collagen fibers. In that respect, Park and Barbul[33] described similar components of the granulation tissue during wound healing that were embedded in loose extra cellular matrix of collagen, fibronectin and hyaluronic acid.

Also, Yüksel et al. ${ }^{[34]}$ stated that on the 7th day of silver sulfadiazine treated injured rats, a severe inflammatory cell infiltration and a slight increase in vascularization were noticed. Fat cells were present in the granulation tissue of subgroup III.A. This was explained by Schmidt and Horsley [35] study which detected proliferated adipocyte precursor cells and mature adipocytes that repopulated in skin wounds following inflammation along with fibroblast migration. They concluded that adipocytes were a key component of the intercellular communication that mediated fibroblast function during skin wound healing.

Immunohistochemical stained sections showed localized immunoreactivity in the mononuclear cells and endothelial cells of blood vessels. Similar findings were described by Basiouny et al. ${ }^{[12]}$ who detected the presence of localized immune reactivity in the structure of the newly formed blood 
vessels and the mononuclear cells after one week of excisional full thickness wound.

In the present study, 14 days after the burn induction [subgroup III.B], H\&E stained sections showed that the scab is still present and newly formed thin epidermis formed of flattened undifferentiated keratinocytes covering the burn area. Similar results were detected by Hassan zadeh et al. [36] who stated that skin wound treated with silver sulfadiazine resulted in thin epidermis that lack differentiation.

In the present study the underlying granulation tissue showed persistence of inflammation with occurrence of many polymorph nuclear cells, numerous blood vessels, fibroblasts and macrophages were observed. Similarly, Younan et al. [33] observed that after 2 weeks, the granulation tissue contained numerous fibroblasts, macrophages, and neutrophils.

Desmouliere et al. [37] who stated that dermal wound healing occurred by local recruitment of fibroblasts from the dermis of the intact adjacent skin to the sites of injury. Also, Wang et al. [38] mentioned that the initial responses of fibroblasts near to the wound site included proliferation and migration into the wound. They added that when they reached wound site, dysregulated dermal fibroblasts were responsible for formation of scar due to their role in wound contraction, extracellular matrix deposition and tissue remodeling. Moreover, Fahimi et al. [30] detected invasive inflammatory cell infiltration and numerous congested capillaries 14 days after burn injury.

Staining by Masson trichrome in subgroup III.B showed fine haphazardly arranged collagen fibers in the granulation tissue. This came in accordance with, Popescu et al. [39] who observed many disorganized thin collagen fibers in the depth of the dermis 2 weeks after burn injury.

Immunohistochemical staining showed moderate localized immunoreactivity in the wall of blood vessels, mononuclear cells and fibroblast. These findings are coincided with those of Fawzy et al. [40] who found that skin wound after 2 weeks, showed high level of VEGF in many dermal cells and in the endothelium of blood vessel.
Twenty-one days after burn injury [subgroup III.C], in the present work, histological examination of H\&E-stained sections revealed spontaneous reepithelization near the healthy edge of the burned areas represented with newly formed epidermis appeared more or less normal with absence of skin appendages. The underlying dermis contained many dilated blood vessels, numerous mononuclear inflammatory cells with absence of skin appendages. The newly formed epidermis originated from the stratum basale in the nearby healthy non-burned epidermis or from the nearby healthy hair follicles stem cells ${ }^{[41]}$.

They also explained the repair and reepithelialization of a wound by migration of stem cells from the hair follicle bulge giving rise to daughter cells, which migrated to the basal layer of epidermis. Moreover, Akhoondinasab et al. [42] described the final step of the skin wound repair which was epithelialization, it involved migration, proliferation, and differentiation of epithelial cells from the wound edges to resurface the defect.

The dermis after 21 days from the burn induction [subgroup III.C] in the present study showed deposition of newly formed thin collagen fibers that were arranged parallel to the surface. This observation was confirmed by Masson trichrome stain and it coincided with Basiouny et al. [12] who found that excisional full thickness wound after 3 weeks, showed deposition of collagen fibers aligned horizontally in one direction. They attributed this finding to failure of collagen remodeling.

Moreover, Sharma and John [32] stated that fibroblasts were stimulated by platelet derived growth factor [PDGF] secreted from platelets and macrophages that existed in the wound. After stimulation, fibroblasts laid down a provisional matrix composed of type III collagen, glycosaminoglycans and fibronectin.

In the current study, immunohistochemical staining of subgroup III.C for VEGF gave a positive reaction was seen in the blood vessels and fibroblasts. Similar findings were described by Basiouny et al. [12] who detected the presence of localized immune reactivity in the blood vessels and the fibroblastic cells after 3 weeks of excisional full thickness wound. 
In this present study, H\&E stained sections of subgroup IV.A and subgroup V.A, 7 days after burn injury and MSCs transplantation, revealed a thick scab covering the burn area with early growth of thickened epidermis over the edges of the burn. These previous findings were in agreement with Isackson et al. ${ }^{[43]}$ who noticed early development of crust after one week in BMSCs- treated skin wound. Basiouny et al. [12] noticed that the reepithelialization started in rats at day 7 postwounding in MSCs treated group and at day 14 post-wounding in non-treated group.

In the present study in subgroup IV.A and subgroup V.A, healthy granulation tissue was formed after MSCs transplantation. These results were in agreement with Akela et al. [44] who explained the role of BMSCs in the acceleration of granulation tissue formation that is extremely resistant to infection, provides a surface over where epithelium can migrate and contains fibroblast producing collagen for wound healing. Accordingly, Shumakov et al. ${ }^{[45]}$ found that BMMSCs enhanced and accelerated the formation of new blood vessels in the granulation tissue of the burn wound bed. Staining by Masson trichrome in subgroup IV.A and subgroup V.A early deposition of newly formed thin deeply stained irregularly distributed collagen fibers. These findings were in agreement with Fossum et al. [46] who found that BMSCs are able to transcribe both collagen types I and III.

VEGF immunopositive reaction was observed in peri-vascular mononuclear cells, fibroblastic cells, and endothelial blood vessel lining after one week in BMSC treatment groups, this were consistent with Sköld et al.[47].who observed that the positive reaction of VEGF may be associated with increased VEGF secretion during wound healing by these cells and with Bao et al.[48] who observed that activated platelets that release VEGF particularly after thrombin stimulation.

H\&E stained sections examination, 14 days after burn induction [subgroup IV. B and subgroup V.B], in the present study showed progress in the healing of the wound represented by the regeneration of the epidermis with all its layers. This coincides with Chen et al. ${ }^{[49]}$ who mentioned that MSCs had the ability to differentiate into keratinocytes and also secreted factors that were essential in the re epithelialization process. They added that factors promoting epithelialization included insulin growth factor 1 [IGF-1], epidermal growth factor [EGF] and Keratinocyte growth factor [KGF].

Also, Pastar et al. [50] stated that there was synergy between growth factors, extracellular matrix, and integrins that played an important role in the regulation of keratinocyte proliferation during re epithelialization by being activated to repair an injury.

In the present study, the granulation tissue in the dermis which was formed 14 days after MSCs transplantation consisted of more collagen fibers, fibroblasts and less inflammatory cells than that of sub group III.B which didn't receive MSCs. In addition, few poly morph nuclear cells were observed in the granulation tissue in the burn area of MSCs treated groups on day 7 post burning and rarely encountered on day 14 post burning. This finding could be due to the immunomodulatory effect of MSCs and its immunosuppressive role by decreasing the number of inflammatory cells in the wound [51]. They found that the maturation and remodeling of wound healing was characterized by a decrease in the cell population and an increase in collagen organization in granulation tissue. Similarly, El Sadik et al. [52] reported that the newly formed dermal layer after MSCs injection showed more collagen fibers and fibroblasts rather than inflammatory cells. Moreover, Shumakov et al. [45] concluded that MSCs transplantation on the surface of deep burn wounds in rats decreased the infiltration of inflammatory cell into the wound, and accelerated the granulation tissue formation.

Accordingly, Liu et al. [6] noted that umbilical cord derived MSCs attenuated the local inflammation in the burned skin by decreasing neutrophil and macrophage infiltration and proinflammatory cytokine production. Zhang et al. [53] detected a decreased expression of TNF- $a$, IL- 6 and other inflammatory markers in the MSCs transplantation group. While simultaneously increased the production of anti-inflammatory cytokines interleukin-10 [IL-10] and IL-4. Also, Nuschke [54] added that MSCs suppressed T cell proliferation to reduce wound site inflammation and reduced Natural killer cell function thus lowering interferon gamma [IFN- $\gamma$ ] 
activity. This led to reduce the levels of systemic inflammatory response and improved the repair process by inhibiting the post-burn inflammation.

Vascularity of subgroup IV.B and subgroup V.B was represented by numerous patent blood vessels that appeared in H\&E sections and was confirmed by immunohistochemical staining which showed a significant strong positive reaction due to the enhanced neovascularization done by MSCs transplantation.

Accordingly, Shumakov et al. [45] found that BMMSCs enhanced and accelerated the formation of new blood vessels in the granulation tissue of the burn wound bed. More ever Wang et al.[55] stated that following injury, the blood supply is the key for wound healing. They added that MSCs secreted some growth factors such as vascular endothelial growth factor [VEGF], basic fibroblast growth factor [FGF] and hepatocyte growth factor [HGF] that promoted neovascularization of injured tissues.

In the present work, 21 days after transplantation of MSCs in the burn wound [subgroup IV.C and subgroup V.C], H\&E stained sections showed well developed regenerated epidermis, which contained recesses for formation of hair follicles. This came in agreement with, Yang et al. [23] who detected epidermal layer and hair follicle-like structure that were formed in the MSCs transplanted group.

In the present study, many non-keratinocytes most probably Langerhans cells were detected in the regenerated epidermis in burn treated with BMMSC [subgroup IV. C and subgroup V.C].

This was explained by Chen et al. [56] who showed that wounds treated with BM-MSC or its conditioned medium had increased abundance of macro-phages. They suggested that BM-MSCs released greater amounts of factors compared to dermal fibroblasts, such as vascular endothelial growth factor alpha [VEGF-a], insulin like growth factor-1 [IGF-1], epidermal growth factor [EGF], keratinocyte growth factor, angiopoietin-1, stromal derived factor-1, macrophage inflammatory protein1alpha and beta and erythropoietin, which increased the recruitment of macrophages to the site of the wound. In addition, Zhang et al. [53] demonstrated that macrophages encountered with
BM-MSCs were of anti-inflammatory M2 phenotype. They added that these macrophages had increased phagocytic activity and increased secretion of anti-inflammatory cytokines while reducing production of pro-inflammatory cytokines.

The dermis of subgroup IV.C and subgroup V.C showed dense coarse collagen fibers nearly filling its whole thickness in H\&E stained sections. This was confirmed by Masson trichrome stain that showed significant increase in collagen area percentage represented by increase in thick collagen deposition in the dermis.

Li et al. [57] observed that injecting angiopoietin1 gene-modified BM-MSCs in excisional full thickness wound significantly increased collagen deposition and resulted in much denser collagen than the untreated group, especially at day 21 after treatment.

Meanwhile, the blood vessels in the dermis of this subgroups in H\&E sections were numerous, uniform and organized which was confirmed by the immune histochemical staining for VEGF that showed significantly strong positive reaction in the walls of blood vessels. This finding coincided with $\mathrm{Li}$ et al. ${ }^{[57]}$ who reported that the capillary density in BM-MSC injected burned group was significantly higher than in the burned untreated group.

Liu et al. [6], Lough et al. [58] detected higher neovascularization in the burned group treated with MSCs than the untreated group by counting the micro vessels. The authors attributed this to the increased level of vascular endothelial growth factor [VEGF] in severe burn wounds that promoted wound angiogenesis and subsequently healing.

In the present study, no scar formation was observed in subgroup IV.C and subgroup V.C. This could be explained by Wu et al. [59] who stated that MSCS provided anti scarring properties by secreting prostaglandin E2 [PGE2], which induced increased expression of IL-10 by T-cell and macrophages. They added that IL-10 down regulated TGF- $\beta$ expression and reprogrammed wound fibroblasts to favor extracellular matrix remodeling and decreased the expression of inflammatory cytokines [such as IL-6 and IL-8] that 
in turn prevented excessive increase of collagen deposition in the wound.

In the present study, many non-keratinocytes most probably Langerhans cells were detected in the regenerated epidermis in burn treated with BMMSC at21 day [subgroup IV. C and subgroup V.C].

Similar finding reported by Ahmed et al. [21]. This was explained by Chen et al. [61] who showed that treating of wounds with BM-MSC or its conditioned medium had increased abundance of macrophages. They indicated that BM-MSCs released more factors than dermal fibroblasts, such as vascular endothelial growth factor alpha [VEGF-a], insulin like growth factor-1 [IGF-1], epidermal growth factor [EGF], keratinocyte growth factor, angiopoietin-1, stromal derived factor-1, macrophage inflammatory protein-1alpha and beta and erythronpoietin, That increased macrophage recruitment at the wound site.

In addition, Zhang et al. [60] demonstrated that macrophages encountered with BM-MSCs were of anti-inflammatory M2 phenotype. They added that these macrophages had increased phagocytic activity and increased secretion of antiinflammatory cytokines while reducing production of pro-inflammatory cytokines.

Surprisingly, in the present study, on comparing the histological effects of both topical and systemic BM-MSC delivery methods on the healing of induced deep second-degree burning were both found to increase healing. Whereas, the topical approach was more successful as $20 \%$ of systemically treated rats observed delayed healing at the end of the third week. Our results agreed with Basiony et al. ${ }^{[12]}$ who found that topical injection of MSCs had better effects than systemic one.

Similar results were observed by Tark et al. [61] who used Human cord blood derived mesenchymal stem cells in topical \& systemic injection to heal diabetic mouse model wounds. The systemic method of delivery mimics the route of endogenous MSCs with final homing to target sites through the circulatory system. MSCs carry the risk of being excluded from circulation during vascular movement in organs such as the lungs, spleen, and liver. This can interrupt their transit or reduce the numbers of cells that finally reach the specific target, which might explain the local injection efficiency when compared with the systemic one.

The healing rate of the MSCs treated group.IV and group. $V$ was higher compared to that of group. III in the current study. Thus, suggesting that MSCs greatly increase the healing of burn wounds.

Accordingly, Shi et al. [62] observed short healing time and high healing rate in burned wounds injected with umbilical cord derived MSCs in mice.

Also, Zhang et al. [60] stated that MSCs transplantation reduces the wound healing time after burn injury and helped the subsequent skin repair and reconstruction.

The findings of this study suggested that MSCs had a great role in the healing of burn wounds and avoiding scar formation. Accordingly, Sasaki et al. [63] showed that when BM-MSCs were injected into the wounds of mice, the MSCs differentiated not only into keratinocytes but also into endothelial cells and pericytes in vivo.

Finally, Stem cells accelerate wound healing via a complex series of pathways that seek to promote neo-angiogenesis, collagen deposition and granulation tissue formation. They alter our immune response by decreasing the severity of the inflammatory cascade. This may decrease the risk of infection. Stem cells are key in regeneration of cutaneous appendages such as hair follicles, sweat and sebaceous glands.

In conclusion, the findings of the present study had proved that Both methods of BMSCs injection were effective in healing of deep $2^{\text {nd }}$ degree skin burn but topical method was more effective. The research still needs a much study on BMSCs to gain the desirable effect of it on the body specially the important organs as the skin.

\section{Conflict of interest}

Authors declare that, there was no conflicts of interest. 


\section{REFERENCES}

1. Golchin A, Farahany TZ, Khojasteh A, Soleimanifar F, Ardeshirylajimi A. The Clinical Trials of Mesenchymal Stem Cell Therapy in Skin Diseases: An Update and Concise Review. Curr Stem Cell Res Ther. 2019; 14[1]: 22-33. [Doi: 10.2174/1574888X13666180913123424].

2. Lateef Z, Stuart G, Jones N, Mercer A, Fleming S, Wise L. The Cutaneous Inflammatory Response to Thermal Burn Injury in a Murine Model. Int J Mol Sci. 2019; 20[3]. pii: E538. [Doi: 10.3390/ijms20030538].

3. Beltran SL, Vilela RAG, de Almeida IM. Challenging the immediate causes: A work accident investigation in an oil refinery using organizational analysis. Work. 2018; 59 [4]:617-636. [DOI: 10.3233/WOR-182702].

4. Nielson CB, Duethman NC, Howard JM, Moncure M, Wood JG. Burns: pathophysiology of systemic complications and current management. J Burn Care Res. 2017; 38[1]: e469-e481. [DOI: 10.1097/BCR. 0000000000000355].

5. Bao P, Kodra A, Tomic-Canic M, Golinko MS, Ehrlich $\mathrm{HP}$, Brem $\mathrm{H}$. The role of vascular endothelial growth factor in wound healing. J Surg Res. 2009;153[2]:34758. [DOI: 10.1016/j.jss.2008.04. 023].

6. Liu L, Yu Y, Hou Y, Chai J, Duan H, Chu W, et al. Human umbilical cord mesenchymal stem cells transplantation promotes cutaneous wound healing of severe burned rats. PLoS One. 2014; 9 [2]: e88348. [DOI: 10.1371/ journal. pone.0088348].

7. Chhabra P, Mehra L, Mittal G, Kumar A. A Comparative Study on the Efficacy of Chitosan Gel Formulation and Conventional Silver Sulfadiazine Treatment in Healing Burn Wound Injury at Molecular Level. Asian J Pharm 2017; 11 [3]: 489-496.

8. Lu W, Zhang YJ, Jin Y. Potential of stem cells for skin regeneration following burns. Expert Rev Dermatol. 2009; 4[2]:97-99. [DOI:101586/EDM.09.9].

9. Revilla G, Afriani N, Rusnita D. Effects of Bone Marrow Mesenchymal Stem Cell to Transforming Grow Factor$\beta 3$ and Matrix Metalloproteinase-9 Expression in Burns. J Med Sci 2018; 18 [4]: 164-171. [DOI: 10.3923/jms. 2018.164.171].

10. Johnson KE, Wilgus TA. Vascular endothelial growth factor and angiogenesis in the regulation of cutaneous wound repair. Adv Wound Care [New Rochelle]. 2014; 3 [10]: 647-661. [DOI:10.1089/wound.2013.0517].

11. Azimi-Nezhad M. Vascular endothelial growth factor from embryonic status to cardiovascular pathology. Rep Biochem Mol Biol. 2014;2[2]:59-69. [PMID: 26989723].

12. Basiouny HS, Salama NM, Maadawi ZM, Farag EA. Effect of bone marrow derived mesenchymal stem cells on healing of induced full-thickness skin wounds in albino rat. Int J Stem Cells 2013; 6[1]:12-25. [DOl: 10.15283/ijsc.2013.6.1.12].

13. Durmus AS, Han MC, Yaman I: Comperative evaluation of collagenase and silver sulfadiazine on burned wound healing in rats. Firat Universitesi Saglik Bilimleri Veteriner Dergisi [2009]; 23, 135-139.

14. Abd-Allah SH, El-Shal AS, Shalaby SM, Abd-Elbary E, Mazen NF, Abdel Kader RR. The role of placentaderived mesenchymal stem cells in healing of induced full-thickness skin wound in a mouse model. IUBMB life 2015; 67[9], 701-709. [DOI:10.1002/iub.1427]

15. Bancroft JD Gamble M. Hamtoxilin and Eosin. Chapter 10, In: Theory and Practice of Histological Techniques, $8^{\text {th }}$ edition - London, Churchill Livingstone, London 2019. pp126-130

16. Drury RA, Wallington EA. Carleton's Histological Techniques. $5^{\text {th }}$ ed. Oxford University Press, Oxford, New York and Toronto, 1980;144-45, 183-85.

17. El-Azab DS, Ayad HA, Abdelnaby AS, El-Gammal SS. Immunohistochemical expression of cadherin-17 in normal and nonmalignant liver tissues. Menoufia Med J. 2016; 29[4], 971. [DOI: 10.4103/1110-2098.202518]

18. Attia MM, Eldien AAS, Haiba DA, Mohamed SM. Effect of stem cell transplantation on amiodarone-induced hepatic changes in adult male albino rats: a histological and immunohistochemical study. Egy J Histol. 2015; 38 [2]: 295-307. [DOI: 10.1097/01.EHX.0000464780. 75492. 5e].

19. Ghabrial MM, Salem MF, El Ela AM, El Deeb SA. The possible therapeutic role of mesenchymal stem cells in amiodarone-induced lung injury in adult male albino rats. Tanta Med J. 2018; 46[3]: 172. [DOI: 10. 4103/ tmj.tmj_4_18]

20. Pereira T, Dos Santos D, Lima MHM, de Pontes-Filho NT, Carneiro AMDA, Correia MTDS. Development of animal model for studying deep second-degree thermal burns. BioMed Research Int. 2012; Article ID 460841, 7 pages. [DOI: 10.1155/ 2012/460841].

21. Ahmed YYD, Mohamed EN Abd Elrahman AM, Abd EI Khalek IG. Histological and immunohistochemical study on the role of mesenchymal stem cells in the repair of experimentally induced skin burn in adult male albino rat. QJM: An International Journal of Medicine 2018; 111 [suppl 1]: i36-i37 [DOI: 10.1093/qjmed/hcy200.226]

22. Johnson RM, Richard R. Partial-thickness burns: identification and management. Adv Skin Wound Care. 2003;16[4]:178-87. [DOI:10.1097/00129334-200307 000-00010]

23. Yang Y, Zhang W,Li Y, Fang G, Zhang K. Scalded Skin of Rat Treated by Using Fibrin Glue Combined with Allogeneic Bone Marrow Mesenchymal Stem Cells. Ann Dermatol. 2014; 26[3]: 289-295 [DOI:10.5021/ ad.2014. 26.3.289] 
24. Heredero FX, Hamann C, Obispo Martin JM, Rodriguez Arias C, Coca Menchero S. Experimental burn models. Annals of Burns and Fire Disasters. 1996; 9[2]. 96-97.

25. Park BH, Saxer C, Srinivas SM, Nelson JS, de Boer JF. In vivo burn depth determination by high-speed fiberbased polarization sensitive optical coherence tomography. J Biomed Opt. 2001; 6[4]:474-479. [DOI: 10.1117/1.1413208]

26. Tanaka R, Fukushima S, Sasaki K, Tanaka Y, Murota H, Matsumoto T, Araki T, Yasui T. In vivo visualization of dermal collagen fiber in skin burn by collagensensitive second- harmonic- generation microscopy. J Biomed Opt. 2013;18[6]:61231. [DOI: 10.1117/1. JBO.18.6.061231.]

27. Xiao M, Li L, Li C, Zhang P, Hu Q, Ma L, Zhang H. Role of Autophagy and Apoptosis in Wound Tissue of Deep Second-degree Burn in Rats. Acad Emerg Med 2014; 21[4]: 383-391. [DOI: 10.1111/acem.12352.]

28. Younan G, Suber F, Xing W, Shi T, Kunori Y, Abrink M, et al. The Inflammatory Response after an Epidermal Burn Depends on the Activities of Mouse Mast Cell Proteases 4 and 5. J Immunol 2010; 185 [12]:76817690. [DOI: 10.4049/jimmunol.1002803.]

29. Arno Al, Amini-Nik S, Blit PH, Al-Shehab M, Belo C, Herer E, Tien CH, Jeschke MG: Human Wharton's jelly mesenchymal stem cells promote skin wound healing through paracrine signaling. Stem Cell Res Ther. 2014 Feb 24;5[1]:28. [DOI: 10.1186/scrt417.]

30. Fahimi S, Abdollahi M, Mortazavi SA, Hajimehdipoor $H$, Abdolghaffari AH, Rezvanfar MA. Wound Healing Activity of a Traditionally Used Poly Herbal Product in a Burn Wound Model in Rats. Iran Red Crescent Med J. 2015; 17[9]: e19960. [DOI: 10.5812/ircmj.19960.]

31. Yaman I, Durmus A.S, Ceribasi S, Yaman M. Effects of Nigella sativa and silver sulfadiazine on burn wound healing in rats. Veterinarni Medicina 2010; 55: 619-624.

32. Sharma RK, John JR. Role of stem cells in the management of chronic wounds. Indian J Plast Surg 2012; 45[2]: 237-243. [DOI: 10.4103/0970-0358. 101286]

33. Park J, Barbul A. Understanding the role of immune regulation in wound healing. Am J Surg 2004;187 [5A]:11S -16S. [DOI: 10.1016/S0002-9610[03]00296-4].

34. Yüksel EB, Yıldırım AM, Bal A, Kuloglu T. The effect of different topical agents [silver sulfadiazine, povidoneiodine, and sodium chloride $0.9 \%$ on burn injuries in rats. Plast Surg Int. 2014; 2014:907082. [DOI: 10.1155/ 2014/907082].

35. Schmidt BA, Horsley V. Intradermal adipocytes mediate fibroblast recruitment during skin wound healing. Development. 2013;140[7]:1517-27. [DOI: 10.1242/ dev. 087593].

36. Hassanzadeh G, Hajmanouchehri F, Beheshtiroi A,
Hassanzadeh N, Shafigh N, Barzroudipour M, Baazm M, Choobineh H. Comparing effects of Silver sulfadiazine, Sucralfate and Brassica oleracea extract on burn wound healing. Life Sci J. 2013; 10[6]:254-259.

37. Desmouliere A, Redard M, Darby I, Gabbiani G. Apoptosis mediates the decrease in cellularity during the transition between granulation tissue and scar. Am J Pathol. 1995; 146[1]:56-66 [PMID: 7856739]

38. Wang J, Dodd C, Shankowsky HA, Scott PG, Tredget EE, Wound Healing Group. Deep dermal fibroblasts contribute to hypertrophic scarring. Lab Invest 2008; 88[12]:1278-1290. [DOI: 10.1038/labinvest.2008.101.]

39. Popescu FC, Busuioc CJ, Mogoşanu GD, Pop OT, Pârvănescu H, Lascăr I, Nicolae Cl, Mogoantă L.: Pericytes and myofibroblasts reaction in experimental thermal third-degree skin burns. Rom J Morphol Embryol. 2011; 52[3]:1011-1017. [PMID:22119818]

40. Fawzy HM, El Shawarby A, Kalleny NK, Shaker SM. Comparative Study on the Effect of Silver Nanoparticles versus Silver Sulfadiazine in Diabetic Wound Healing in Albino Rat: a Histological Study. Egy J Hospital Med. 2018;73[2], 6042-60. [DOI: 10.12816/ ejhm. 2018.12498]

41. Ito M, Liu Y,Yang Z, Nguyen J, Liang F, Morris R.J, Cotsarelis $\mathbf{G}$. Stem cells in the hair follicle bulge contribute to wound repair but not to homeostasis of the epidermis. Nat. Med. 2005;11[12], 1351-1354. [DOI: 10.1038/ nm1328].

42. Akhoondinasab MR, Khodarahmi A, Akhoondinasab M, Saberi M, Iranpour M. Assessing effect of three herbal medicines in second and third degree burns in rats and comparison with silver sulfadiazine ointment. Burns. 2015; 41[1]:125-131. [doi: 10.1016/j.burns. 2014. 04.001]

43. Isackson D, Cook KJ, McGill LD, Bachus KN. Mesenchymal stem cells increase collagen infiltration and improve wound healing response to porous titanium percutaneous implants. Med Eng Phys. 2013;35 [6]: 743-53. [DOI: 10.1016/j.medengphy.2012.08.002].

44. Akela A, Nandi SK, Banerjee D, Das P, Roy S, Joardar SN, et al. Evaluation of autologous bone marrow in wound healing in animal model: a possible application of autologous stem cells. Int Wound J. 2012;9: 505-516. [DOI: 10.1111/j.1742-481X.2011.00909.x]

45. Shumakov VI, Onishchenko NA, Rasulov MF, Krasheninnikov ME, Zaidenov VA. Mesenchymal bone marrow stem cells more effectively stimulate regeneration of deep burn wounds than embryonic fibroblasts. Bull. Exp. Biol. Med. 2003; 136[2]:192-195. [DOI:10.1023/a:1026387411627]

46. Fossum TW, Hedlund CS, Johnson A., Schulz KS, Seim HB, Willard MD, Baer A, Carroll GL. Manual of small animal surgery. $3^{\text {rd }}$ ed. St. Louis, Missouri: Elsevier/Mosby. 2007;159-259. 
47. Sköld MK, von Gertten C, Sandberg-Nordqvist AC, Mathiesen T, Holmin S. VEGF and VEGF receptor expression after experimental brain contusion in rat. $\mathrm{J}$ Neurotrauma 2005; 22:353-367. [DOI:10.1089/neu. 2005.22.353]

48. Bao P, Kodra A, Tomic-Canic M, Golinko MS, Ehrlich HP, Brem H. The role of vascular endothelial growth factor in wound healing. J Surg Res. 2009; 153:347-358. [DOI: 10.1016/j.jss.2008.04.023.]

49. Chen D, Hao H, Fu X, Han W. Insight into Reepithelialization: How Do Mesenchymal Stem Cells Perform?". Stem Cells Int. 2016; 6120173. [doi: 10.1155/2016/6120173.]

50. Pastar I, Stojadinovic O, Yin NC, Ramirez H, Nusbaum AG, Sawaya A, et al. Epithelialization in Wound Healing: A Comprehensive Review. Adv Wound Care [New Rochelle] 2014; 3[7]:445-464. [DOI:10.1089/ wound. 2013.0473].

51. Kumar V, Cotran RZ, Robbins SL. Basic Pathology. $7^{\text {th }}$ ed. Saunders, Philadelphia, London, Toronto, Montreal, Sydney, Tokyo. 2003; p873.

52. El Sadik AO, El Ghamrawy TA, Abd El-Galil TI. The Effect of Mesenchymal Stem Cells and Chitosan Gel on Full Thickness Skin Wound Healing in Albino Rats: Histological, Immunohistochemical and Fluorescent Study. PLOS ONE 2015; 10[9]: e0137544. [DOI: 10.1371/journal.pone.0137544]

53. Zhang J, La X, Fan L, Li P, Yu Y, Huang Y, Ding J, Xing Y. Immunosuppressive effects of mesenchymal stem cell transplantation in rat burn models. Int $\mathrm{J}$ Clin Exp Pathol. 2015; 8[5]:5129-5136. [PMID:26191208]

54. Nuschke A. Activity of mesenchymal stem cells in therapies for chronic skin wound healing. Organogenesis 2014; 10[1]:29-37. [DOI: 10.4161/ org. 27405.]

55. Wang $Y$, Wang M, Abarbanell AM, Weil BR, Herrmann JL, Tan J, et al. MEK mediates the novel cross talk between TNFR2 and TGF-EGFR in enhancing vascular endothelial growth factor [VEGF] secretion from human mesenchymal stem cells. Surgery 2009; 146[2]:198205. [DOI: 10.1016/j.surg.2009.04.013.]
56. Chen L, Tredget EE, Wu PY, Wu Y. Paracrine factors of mesenchymal stem cells recruit macrophages and endothelial lineage cells and enhance wound healing. PLoS One. 2008; 3[4]: e1886. [DOI: 10.1371/journal. pone. 0001886.]

57. Li P, Zhang R, Sun H, Chen L, Liu F, Yao C, Du M, Jiang X. PKH26 can transfer to host cells in vitro and vivo. Stem Cells Dev 2013; 22[2]:340-344. [DOI: 10.1089/scd.2012.0357]

58. Lough DM, Yang M, Blum A, Reichensperger JD, Cosenza NM, Wetter N, et al. Transplantation of the LGR6+ epithelial stem cell into full-thickness cutaneous wounds results in enhanced healing, nascent hair follicle development, and augmentation of angiogenic analytes". Plastic and Reconstructive Surgery 2014; 133 [3]: 579-590. [DOI: 10.1097/PRS. 0000000000000075]

59. Wu Y, Huang S, Enhe J, Ma K, Yang S, Sun T, Fu X. Bone marrow-derived mesenchymal stem cell attenuates skin fibrosis development in mice. Int Wound J. 2014; 11[6]:701-710. [DOI: 10.1111/iwj.12034.]

60. Zhang QZ, Su WR, Shi SH, Wilder-Smith P, Xiang AP, Wong $A$, et al. Human gingiva-derived mesenchymal stem cells elicit polarization of M2 macrophages and enhance cutaneous wound healing. Stem Cells 2010; 28:1856. [DOI: 10.1002/stem.503]

61. Tark KC, Hong JW, Kim YS, Hahn SB, Lee WJ, Lew DH. Effects of human cord blood mesenchymal stem cells on cutaneous wound healing in leprdb mice. Ann Plast Surg. 2010; 65:565-572 52. [DOI: 10.1097/ SAP. 0b013e3181d9aae2.]

62. Shi S, Jia S, Liu J, Chen G. Accelerated Regeneration of Skin Injury by Co-transplantation of Mesenchymal Stem Cells from Wharton's Jelly of the Human Umbilical Cord Mixed with Microparticles. Cell Biochem Biophys. 2015; 71 [2]:951-956. [DOI: 10.1007/s12013-014-0292-y.]

63. Sasaki M, Abe R, Fujita Y, Ando S, Inokuma D, Shimizu H. Mesenchymal stem cells are recruited into wounded skin and contribute to wound repair by transdifferentiation into multiple skin cell type. J Immunol. 2008; 180[4]:2581-2587. [ DOI: 10.4049/jimmunol.1 80.4.2581] 